\title{
Promising the Future: Virginity Pledges and First Intercourse ${ }^{1}$
}

Peter S. Bearman and Hannah Brückner

Columbia University

Since 1993, in response to a movement sponsored by the Southern Baptist Church, over 2.5 million adolescents have taken public "virginity" pledges, in which they promise to abstain from sex until marriage. This paper explores the effect of those pledges on the transition to first intercourse. Adolescents who pledge are much less likely to have intercourse than adolescents who do not pledge. The delay effect is substantial. On the other hand, the pledge does not work for adolescents at all ages. Second, pledging delays intercourse only in contexts where there are some, but not too many, pledgers. The pledge works because it is embedded in an identity movement. Consequently, the pledge identity is meaningful only in contexts where it is at least partially nonnormative. Consequences of pledging are explored for those who break their promise. Promise breakers are less likely than others to use contraception at first intercourse.

Gonna give you all my love, boy/My fear is fading fast/Been saving it all for you/'Cause only love can last.

(Madonna, "Like a Virgin")

\section{INTRODUCTION}

Since 1993, in response to an organized social movement sponsored by the Southern Baptist Church, well over 2.5 million adolescents have taken

\footnotetext{
${ }^{1}$ Data for this article are drawn from the National Longitudinal Study of Adolescent Health (Add Health), a program project designed by J. Richard Udry and Peter Bearman and funded by a grant from the National Institute of Child Health and Human Development to the Carolina Population Center, University of North Carolina at Chapel Hill (HD31921), with cooperative funding participation by the National Cancer Institute; the National Institute of Alcohol Abuse and Alcoholism, the National Institute on Deafness and other Communication Disorders, the National Institute on Drug Abuse, the National Institute of General Medical Sciences, the National Institute of Mental Health; the Office of AIDS Research, National Institutes of Health (NIH),

(C) 2001 by The University of Chicago. All rights reserved. 0002-9602/2001/10604-0001\$02.50
}

AJS Volume 106 Number 4 (January 2001): 859-912 
public "virginity" pledges, in which they promise to abstain from sex until marriage. By the standard set by most social movements, the pledge movement has been a resounding success. Heralded in the popular press as a movement of, for, and by adolescents, the pledge movement has expanded to include hundreds of church, school, and college chapters. It is associated with the development of new products and cultural symbols (most notably in music) and is home to numerous interlocked Internet pages where adolescents can pledge online, purchase pledge merchandise, and interact with other pledgers in pledge-dedicated chat rooms. Pledgers can even go to summer camps where only other pledgers can be found. The movement has been successful in organizing mass rallies in which speakers extol the benefits of abstinence to stadiums full of eager adolescents. Its growth rate has been phenomenal, and with it, the movement has spawned a whole new subculture in which it is "cool"to say no to sex, and where, according to one account, "virginity is hot" (Young and Modern, May 1998, in an issue featuring the 100 secrets of Leonardo DiCaprio).

The pledge movement is really a movement organized by adults for adolescents and so, not surprisingly, while pledging is for adolescents, the movement is also attractive to many adults. ${ }^{2}$ Movement rhetoric stresses orientations that are loosely labeled as "family values." Supporters of the pledge like the idea that adolescents can take individual responsibility for their sexual life simply by promising to say no thank you to sex-at least until marriage. Others, on the other hand, are not as sympathetic to the pledge movement. On one hand, pledge critics simply do not believe that something as simple as a pledge can work. In part, they feel uncomfortable endorsing an element of a program (in this case, the pledge) that is based on assumptions that are antithetical to a liberal vision of the world, for example, the assumption that sex should only occur in the context of marriage. Critics do not necessarily oppose the idea of "saving" sex until marriage, but they think that it is an unrealistic foundation for social

the Office of the Director, NIH; the National Center for Health Statistics, Office of Minority Health, Centers for Disease Control and Prevention, Health and Human Services (HHS); Office of the Assistant Secretary for Planning and Evaluation, HHS; and the National Science Foundation. Additional funding for the analyses reported in this article was provided by the Office of Population Affairs. The authors thank Chris Bachrach, Guang Guo, John Hutchins, Joe Rodgers, J. Richard Udry, and Harrison White for helpful comments. Address all correspondence to Peter Bearman, Institute for Social and Economic Research and Policy, 814 IAB, Columbia University, New York, New York 10027. E-mail: psb17@columbia.edu

${ }^{2}$ The pledge movement is loosely organized. More than 80 autonomous organizations sponsor public pledges, support chapter formation, and participate in organizing rallies of varied scale. Movement organizers claim disinterest in the number of adolescents who have taken a pledge. They keep no formal records, and they have few formal mechanisms in place to coordinate the efforts of participating organizations. The pledge movement is one of the activist arms of the more general abstinence-only movement. 
policy. In part, critics find themselves uncomfortable with the pledge because many pledge supporters think that sex education sends the wrong message to adolescents. ${ }^{3}$ And critics do not like the fact that the pledge movement rests on, and reinforces, the imagery of romantic love ${ }^{4}$ not because critics of the pledge are cynics, but because pledge rhetoric seems to be associated with traditional gender roles in adolescence as well as young adulthood. ${ }^{5}$

Whether pledge supporters or critics, most adults are concerned about adolescent sex, here defined as intercourse. ${ }^{6}$ Critics are more concerned about the observable consequences of sex: heightened risk for teenage pregnancy, abortion, and sexually transmitted diseases (STDs) and increased likelihood of participation in other risk activities, such as drinking, smoking, and substance abuse (Resnick et al. 1997; Tubman, Windle, and Windle 1996a, 1996b; AGI 1994; Martin 1996; Thompson 1995). In this view there is nothing wrong with sex per se. ${ }^{7}$ The problem with sex is that it has often has negative consequences, especially for girls, who typically feel worse after sex than before sex (Joyner and Udry 1998), and who face the risk of unwanted pregnancy. Pledge supporters do not articulate their opposition to sex in terms of the consequences of sex, because this would appear to legitimize "good" sex. Instead, they stress moral systems that justify saying no thank you to sex in and of itself.

To anticipate the main empirical findings reported in this article, there might be something for everyone. Pledge supporters will find comfort in the fact that the pledge has a substantial effect on the timing of first intercourse. Adolescents who pledge, controlling for all of the usual char-

\footnotetext{
${ }^{3}$ On this issue, feelings sometimes run strong. On October 26, 1998, after hearing an earlier version of this article read at a Planned Parenthood of NYC workshop, the president and CEO of SIECUS (Sexuality Information and Education Council of the United States) led the assembled crowd of 300 or so participants in a rousing chant: "Abstinence programs do not work."

${ }^{4}$ An irony is that, within the adolescent world, it is the rhetoric of romantic love that provides boys with the key cultural mechanism by which they "work out a yes" from girls (Kaminer 1996; Thompson 1995; Martin 1996).

${ }^{5}$ Critics are also concerned that pledging sets standards that are unrealistic for most adolescents. This may lead them to marry too young, inducing as a consequence marriages with higher chances of divorce. In 1988, the average time between sexual maturity and marriage was 11.8 years for young women and 12.5 years for young men (AGI 1994), which many believe is a long time to wait for sex.

${ }^{6}$ Of course "sex," also involves more than intercourse. Most teenagers, and some adults, think otherwise for the most part, though, and in this article we focus only on intercourse.

${ }^{7}$ Brooks-Gunn and Paikoff (1993), e.g., define "sexual well-being" not in terms of sexual behavior per se but with respect to the consequences of such behavior for adolescents. In such a view, the task is to help adolescents avoid negative consequences of such behavior.
} 
acteristics of adolescents and their social contexts that are associated with the transition to sex, are much less likely than adolescents who do not pledge, to have intercourse. The delay effect is substantial and robust. Pledging delays intercourse for a long time. In this sense, the pledge works. ${ }^{8}$ Critics of the pledge should find solace from two important caveats. First, the pledge effect is strongly conditioned by age. Pledging does not work for adolescents at all ages. Second, pledging delays intercourse only in contexts where there are some, but not too many, pledgers. Too few, and too many, pledgers in the adolescent world can negate the pledge effect. The pledge effect is largely contextual. ${ }^{9}$

We reach these conclusions with data from the National Longitudinal Study of Adolescent Health (hereafter, Add Health), which was collected at the height of the pledge movement, the period between 1994 and 1996 (Bearman, Jones, and Udry 1997). Add Health provides detailed information on the social contexts in which adolescents are embedded. The clustered design of Add Health allows us to investigate the effect of pledging, in the same interacting communities, on pledgers and nonpledgers alike. The longitudinal design of Add Health allows us to order cause and effect without ambiguity. Because our analyses operate on complex data structures at multiple levels of observation, showing the findings we identify involves a number of steps. These steps are outlined below.

We first briefly review the literature on sexual debut. Because the pledge is embedded in an identity movement, we consider the specific aspects of such movements that provide the foundation for both their success and failure. We then describe the Add Health study and the design and methods of our analysis. We then describe the transition to first sexual intercourse and look at differences between pledgers and others. ${ }^{10}$ Because we restrict our analyses of pledging to adolescents for whom we can un-

\footnotetext{
${ }^{8}$ Later, we show that there are no obvious psychological downsides to pledging and then having intercourse anyway. Pledgers who break their promise (hereafter, promise breakers) and end up having intercourse feel no worse about themselves than other adolescents who have intercourse. But, promise breakers are less likely than others to use contraception at first intercourse. This means that promise breakers are at greater risk to the negative consequences of sex. That pledgers who have sex are likely to be contraceptively unprepared is to be expected, for it is hard to imagine how one could both pledge to be a virgin until marriage and carry a condom while unmarried.

${ }^{9}$ The pledge does not operate by changing individuals in obvious and easy-to-measure ways that are known to be correlates of adolescent sexual behavior. Just thinking about girls, those who are smart, unattractive, on sports teams, doing well in school, close to their parents, and have high self-esteem are less likely than others to have sex. Adolescents do not get smarter once they have pledged, they do not become less attractive, they do not gain or lose self-esteem, they do not suddenly join sports teams, do better in school, have better relations with their parents, or feel more attached to their schools. But they do delay intercourse.

${ }^{10}$ App. B reports a full multivariate model of the determinants of pledging.
} 
ambiguously order intercourse and pledging, our sample is selective. We discuss the impact of sample selectivity for our results in appendix A. The impact is negligible for nonblack adolescents.

We then turn to multivariate event history models of the transition to first intercourse. We focus on identifying main effects and observe the strong impact of the pledge on the transition to first intercourse, controlling for all of the relevant factors associated with pledging. As the transition dynamics are different for adolescent females than for males, we next test a wide range of gender interactions with a model focusing on individuallevel and partnership characteristics. Because pledge rhetoric invokes the idiom of romantic love, we focus on the interaction between pledging, emotional commitment within relationships, and the transition to intercourse. The results show significant race and gender differences. Specifically, whereas emotional commitment within relationships is positively associated with the transition to sex within that relationship for most adolescents, the opposite is true for black males. Black males are not likely to have intercourse in relationships characterized by emotional closeness. They are likely to have intercourse in relationships that invoke little emotional commitment.

Next, we explore context effects on the transition to first intercourse, specifically, the proportion of pledgers in a respondents' school for both pledgers and others. Here we identify the core contextual effect described above. We also show how pledging is driven by the proportion of pledgers in school.

We then relax one important assumption underlying the event history models previously discussed. Specifically, we explore possible age dependencies of the estimated parameter effects. Here, we ask whether the presence and magnitude of factors affecting the transition to first intercourse depends on the age in which their influence is exerted. We show that most factors are critically sensitive to age. The pledge effect also depends on an adolescent's age.

After the detailed analysis of the effects of pledging on sexual initiation, we look specifically at health outcomes and the health behavior of pledgers and others who have had intercourse. It is easy to say that the pledge is not likely to work in the long run because eventually most everyone will transition to intercourse before marriage. But this is misguided, for even if pledging works only to delay intercourse, and even if pledgers eventually have sex before they marry, pledging may be a way to bridge some of the difficult years in early adolescence without (unwanted) sexual activity. ${ }^{11}$ Still, critics have argued that promise breakers will feel guilty after

\footnotetext{
${ }^{11}$ About one-quarter of all adolescents report that they have felt pressure from peers to have sex (AGI 1994). Pledging may provide a useful tool for fending off such peer
} 
sex and thus lose self-esteem. Consequently, we first ask whether pledgers are worse off in terms of the consequences of sexual debut for psychological well-being than nonpledgers. We show that promise breakers are not worse off with respect to self-esteem.

Finally, using a sample of adolescents who have had first intercourse within our observation window only, we model contraceptive behavior at first intercourse and examine whether pledgers are less contraceptively prepared than others. We show that there are differences between promise breakers and others in their contraceptive behavior. Pledgers are less likely to use contraceptives. We conclude by focusing on implications of identity movements for social policy.

\section{SOCIAL INFLUENCES ON ADOLESCENT SEXUAL DEBUT}

Our empirical work builds from a large literature on the determinants of first intercourse. The key insight that we exploit is the recognition that adolescents are embedded in multiple social contexts-families, schools, peer groups, and romantic relationships-and that these social contexts, in interaction with individual characteristics, are important determinants of adolescent behavior (Udry and Bearman 1998; Perry, Kelder, and Komro 1993; Brooks-Gunn and Paikoff 1993). Our goal in this short section is to identify the salient influences on sexual debut discussed in previous work in order to provide the foundation for a baseline model from which we can assess the pledge effect.

Many adolescent "problem behaviors," like sexual activity, drinking, smoking, are behaviors that are socially sanctioned, acceptable, and enjoyable for many adults (Udry and Bearman 1998). While not socially sanctioned, it is reasonable to think that they are also enjoyable for adolescents. Consequently, one idea is that in the absence of social control, all adolescents would engage in nonnormative (enjoyable) behavior. ${ }^{12}$ It follows that one determinant of sexual behavior is the extent to which adolescents are subject to, and influenced by, social controls that operate to constrain opportunity to engage in nonsanctioned behavior, or heighten the costs of such behavior. Conversely, social influence (especially the influence of partners, for sexual behavior) may operate to enhance the perceived benefits of nonnormative behavior. Many of the social context variables that we use in our baseline model derive from the social control

pressure. For an analysis of peer effects on sexual debut and pregnancy risk among girls, see Bearman and Brückner (1999).

${ }^{12}$ See Udry (1988) for a summary and critique of social control theory; Hofferth (1987) for a summary of research with respect to sexual initiation, and Brooks-Gunn and Paikoff (1993) for a summary with respect to the sexual well-being of adolescents. 
perspective. The central idea is to capture through measurement the social influences on adolescents that shape the costs, benefits, and opportunities for sexual initiation.

Table 1 identifies the main social (and developmental) influences on sexual debut. Within each domain, core variables identified in prior literature and their hypothesized relationship to sexual debut that we use in our analyses are listed. For each effect we note if it is hypothesized to be protective (negative) or risk enhancing (positive). Many of these factors are likely to influence sexual behavior differently across the adolescent life course. There are also strong indications in the literature that the transition dynamic for girls is different than that for boys. Consequently, gender interactions across many of the variables capturing social influence are expected. Potential gender interactions are listed in table 1. Comparatively little work has been done that focuses on age dependencies with respect to adolescent transition to first sex, but such dependencies are likely important. Physical and pubertal development, for example, is likely to be more differentiated among younger teens (Udry and Billy 1987). Consequently, it is reasonable to expect that the effect of physical development on the transition to first sex is stronger for younger adolescents than for older adolescents. Likewise, as adolescents get older, peers may become more influential, while parents' influence may decline as adolescent autonomy increases (Hofferth 1987; Bearman and Brückner 1999). Consequently, we would expect to observe enhanced peer influence and declining parental influence on sexual behavior as adolescents age. For each influence listed, we note whether or not there is an expected age dependency.

\section{FAMILY CONTEXT AS SOCIAL INFLUENCE ON FIRST INTERCOURSE}

Family context has been shown to have consistent and strong effects on the timing of first intercourse. Teens living in single-parent families or with stepparents initiate sexual activity earlier than those in two-parent families (AGI 1994; Brooks-Gunn and Paikoff 1993; Hayes 1987; Harris 1996; Miller 1998). Social control theory provides the central mechanism for this effect: adolescents in nontraditional families tend to be subject to less supervision, and/or more permissive attitudes toward sex, by adults. Less supervision provides greater opportunity for engagement in nonsanctioned behaviors, including sex. Adolescents' relationship to their parents, net of socioeconomic background and family context, is also seen as an important correlate of sexual behavior. Adolescent feelings of closeness and connectedness to parents has been shown to delay sexual activity, as 
TABLE 1

Social Influences on Sexual Debut

\begin{tabular}{|c|c|c|c|c|}
\hline & $\begin{array}{l}\text { Relationship to } \\
\text { Sexual Debut }\end{array}$ & $\begin{array}{l}\text { Gender } \\
\text { Interaction }\end{array}$ & $\begin{array}{c}\text { Age } \\
\text { Dependency }\end{array}$ & Main Source(s) \\
\hline \multicolumn{5}{|l|}{ Individual-level characteristics: } \\
\hline Cognitive ability $\ldots \ldots \ldots \ldots$ & - & Yes & No & Halperin et al. (2000) \\
\hline Maturity ......... & + & Yes & Yes & Udry and Billy (1987) \\
\hline 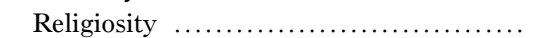 & - & Possible & No & Thornton and Camburn (1989) \\
\hline Self-esteem & - & Yes & No & Martin (1996) \\
\hline Academic achievement & - & Possible & No & $\begin{array}{l}\text { Resnick et al. (1997), Whitehead and Ooms } \\
\text { (1999) }\end{array}$ \\
\hline School attachment & - & Possible & No & $\begin{array}{l}\text { Resnick et al. (1997), Whitehead and Ooms } \\
\text { (1999) }\end{array}$ \\
\hline Extracurricular (sports) & - & Possible & No & Martin (1996), Resnick et al. (1997) \\
\hline \multicolumn{5}{|l|}{ Family variables: } \\
\hline Two biological parents & - & No & No & Miller (1998), Thorton and Camburn (1987) \\
\hline Step- or foster family $\ldots \ldots \ldots \ldots \ldots \ldots \ldots$ & + & No & No & See above \\
\hline Single-parent family $\ldots \ldots \ldots \ldots \ldots \ldots \ldots$ & + & No & No & See above \\
\hline Closeness to parents & - & Possible & Yes & Miller (1998), Resnick et al. (1997) \\
\hline Perceived parental disapproval of sex $\ldots$ & - & Possible & Yes & $\begin{array}{l}\text { Jaccard et al. (1996), Dittus and Jaccard } \\
\text { (1998), Miller (1998) }\end{array}$ \\
\hline
\end{tabular}


Sociodemographic background

White

African-American

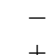

No

Asian

Hispanic ....

No

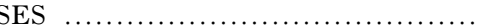

$+1-\quad$ Yes

Network and romantic relationships:

In romantic relationship

$N$ prior partners

Embeddedness of relationship

Emotional commitmen

Popularity

Upchurch et al. (1998), Moore et al. (1998)

See above, and Brewster (1994), Furstenber

et al. (1987), AGI (1994)

See above

See above

Miller (1998)

Bearman and Brückner (1999)

Furstenburg (1976)

Whitehead and Ooms (1999)

Hofferth (1987), Thompson (1995)

Newcomer et al. (1983), Brown and Theobald (1999) 
well as parental disapproval of sex (Resnick et al. 1997; Jaccard, Dittus, and Gordon 1996) and adolescents' perception of their parents' disapproval of sex (Dittus and Jacquard 1998). ${ }^{13}$ If parent attitudes toward sex are not perceived to be strongly and consistently negative, adolescents may also think that the cost of early sexual initiation is lower. In general, connectivity to parents and siblings is protective because it increases the costs of behaviors that are not socially sanctioned. Parents' educational attainment and occupational status have also been shown to delay sexual initiation (Miller 1998; Hofferth 1987). Typically, the costs associated with negative sequelae arising from early sexual initiation (including but not limited to pregnancy) are higher for adolescents from high socioeconomic status (SES) backgrounds. Consequently, the social control perspective hypothesizes that SES is positively associated with age at first sex.

\section{PEER AND PARTNERSHIP INFLUENCES}

Consistent with the expectations of control theory, Bearman and Brückner (1999) show that peer influences (net of family, individual, and social demographic factors) on the transition to first intercourse are generally "positive"- that is, they work to delay age at first intercourse. Connections to peers, as with connections to parents, raise the costs of engaging in nonsanctioned behaviors. In contrast, partnership effects are generally "negative"- that is, they hasten the transition to first intercourse. The more frequently and the earlier adolescents date, the earlier they have intercourse. Commitment to a romantic relationship also plays a role in the timing of first intercourse (Furstenberg 1976; Spanier 1975). Likewise, partner and partnership characteristics are seen to play a key role in the timing of first intercourse. Critical in this regard are the extent to which the partnership is embedded in larger social networks and whether it is characterized by emotional commitment. Partnerships that draw adolescents away from peers (i.e., that isolate young persons) are more likely to be associated with sex. Except for black males, emotional commitment within the partnership, controlling for partnership duration, is positively associated with the transition to sex within that partnership. These partnership effects are thought to operate on adolescents by changing their perception of the costs and benefits of intercourse.

\footnotetext{
${ }^{13}$ Adolescent perceptions of parental attitudes about sex are accurate less than half the time. There are few studies that explore gender differences in parents' normative influence on teenagers' sexual behavior, although social control may be stronger, and undesirable behavior more negatively sanctioned, for girls (Martin 1996). In any case, Udry (1988) shows that social control indicators are more important for girls than for boys, whose transition appears to be more governed by opportunity and hormones.
} 
Virginity Pledges

\section{INDIVIDUAL, BIOLOGICAL, AND SOCIAL DEMOGRAPHIC INFLUENCES}

Independent of background and family structure, adolescents who have reached puberty are more at risk to intercourse than those who have not. ${ }^{14}$ Smarter adolescents are more likely to delay intercourse (Bearman and Brückner 1999; Halpern et al. 2000). Cognitive skills, interests outside the dating culture, as well as self-esteem are seen to be important delaying factors of sexual initiation for girls. Academically inclined girls are less interested in, and less interesting for, boys (Hayes 1987; Hofferth 1987). In general, the more adolescents do (constraining their opportunities and increasing their investments in socially sanctioned activities) the later they have intercourse. Participation in extracurricular activities- both academic clubs and sport teams-delays intercourse (Bearman and Brückner 1999), as do a cluster of variables associated with attachment and commitment to school (Resnick et al. 1997). These attachments draw adolescents into a wider circle of peers and activities, all of which raise the costs associated with early sexual debut. More religious adolescents tend to engage in sexual activities later than do their less religious counterparts (Thornton and Camburn 1989; Miller 1998; Bearman and Brückner 1999). Behavioral measures of affiliation with one's religion seem to be more important than membership in specific denominations (Resnick et al. 1997; Hayes 1987; Hofferth 1987). This suggests that it is not religious prescriptions against sex per se that are salient for delaying intercourse, but the effect of increased connectivity to others arising from participation in church and community groups.

As noted above, these influences are likely to operate differently for adolescents of different ages. Connections to peers and partners are expected to become more salient with age, whereas family influences are expected to be strongest for younger adolescents. Likewise, different pathways to sexual intercourse for boys and girls are expected. In general, contextual factors are thought to be more salient for girls, since the risks associated with sexual activity are disproportionately shared by females. Consequently, social influences that shape adolescent investments in others-whether peers, partners, or parents-are likely to have a greater impact on transition dynamics for girls than for boys.

Our interest in this article is in modeling the effect of taking a virginity pledge on the transition to first intercourse by sex, age, and social context. To be able to estimate the independent effect of a pledge, we need to estimate baseline models for sexual debut. The influences described above, arising in part but not exclusively from control theory, are those most

${ }^{14}$ This is more true for whites than for blacks (Udry 1988). 
often seen to shape transition dynamics, and they provide the conceptual foundation for our measurement of the peer, partner, family, and associational contexts in which adolescents find themselves. Because social demographic and developmental variables play an important role in structuring opportunity, interest, and capacity, to have sex, our models control for well-established covariates of sexual debut-pubertal development, age, intelligence, race, self-esteem, SES, and a battery of attitudes toward sex, including but not limited to the perceived costs, benefits, and risks of sexual activity.

\section{IDENTITY MOVEMENTS}

The pledge is not a government program. Adolescents who pledge can get pledge cards, but they are not required to show them to anyone. Schools do not sponsor pledges, although they may allow pledge groups and clubs to use their grounds before or after school. They offer no special incentives for pledging, and pledgers are not rewarded for pledging by schools. Pledge groups may arise from church youth groups, but they are not isomorphic with them, and many nonpledgers and pledgers alike belong to church groups. ${ }^{15}$ Instead, the institutional foundation of the pledge is the local pledge group. These are only loosely coordinated with each other though weak national leadership. The movement recruits pledgers to local groups through the Internet, through church groups, through Christian music and rallies, but mostly through the energies of adults and adolescents in the community. The incentives the movement selectively provides to its adherents are identity and fellowship with other pledgers. The pledge identity is induced and sustained through interacting with other pledgers in the community who distinguish themselves from nonpledgers by their public pledge and their commitment to the group. The pledge movement, in this sense, is an identity movement - that is, a movement that provides a frame for self-understanding (and consequently action in pursuit of that understanding) effective only in the context of, and interaction with, similar others who constitute a self-conscious community differentiated from others. The key to identity movements is that they need the other to induce the "self" (Hardin 1995; Laitin 1998; Bearman 1991).

Consequently, identity movements are prone to self-limiting dynamics governing recruitment and commitment. Specifically, as a group becomes successful, commitment to the identity declines. On one hand, the unique

\footnotetext{
${ }^{15}$ We considered membership in youth church groups as an independent variable affecting pledging and/or pledge effectiveness, but it is not significant.
} 
nature of the identity disappears as it becomes more normative (Hardin 1995; Calhoun 1991). Consequently, it no longer commands a strong grip on behavior. On the other hand, as the movement becomes more normative, followers come into increased routine contact with nonfollowers, in-group interactions become less dominant, and new influences come to bear (Kim and Bearman 1997; Blau 1977). Recruitment dynamics shift as well, associated with the same threshold effect that governs commitment. If the movement successfully bridges the gap between heterodoxy and orthodoxy, there are no more reasons to join. It appears that identity movements are, by their nature, minority movements.

If, as we argue, the pledge movement is an identity movement, it should be characterized by the same self-limiting dynamics governing recruitment and commitment described above. Specifically, within each focal point (the local community) we ought to be able to observe two interrelated outcomes: declining significance of the pledge effect at the point that pledging becomes normative, and declining impact of the number of pledgers on the probability of pledging (recruitment) after the pledge becomes normative. We test for these expectations subsequently and find that they are confirmed.

\section{DATA, DESIGN, AND METHODS}

Data for the analyses reported on in this article are drawn from Add Health, a nationally representative study of American adolescents in grades 7-12. Add Health provides data from three waves of data collection. Adolescents were included based on a multistage cluster sampling design. Add Health is a school-based study. The primary sampling frame was derived from the Quality Education Database, which lists all high schools in the United States. From this list, Add Health selected a stratified sample of 80 high schools (defined as schools with an eleventh grade and more than 30 students) with probability proportional to size. Schools were stratified by region, urbanicity, school type (public, private, parochial), ethnic mix, and size. For each high school selected, Add Health identified and recruited one of its feeder schools (typically a middle school) with probability proportional to its student contribution to the high school, yielding one pair of schools in 80 different communities. Schools varied in size from fewer than 100 students to more than 3,000 students. The Add Health sample includes private, religious, and public schools from communities located in urban, suburban, and rural areas of the country. The schools, and the students in them, are representative samples. Add Health replaced schools or school pairs in each strata where a school did 
not agree to participate in the survey; however, nearly $80 \%$ of the schools that were contacted by Add Health agreed to participate in the study.

From September 1994 until April 1995, in-school questionnaires were administered to all students in each sampled school. Each school administration occurred on a single day within one 45-60-minute class period. Students not in school on the day of the administration did not complete the in-school instrument. Over $80 \%$ of all students completed the questionnaire. Seven schools did not allow us to survey students in the school but did provide us with a roster; thus we have completed in-school questionnaires from over 90,000 students attending 141 schools. $^{16}$

The in-school questionnaire provided measurement on the social and demographic characteristics of respondents. Students were asked about the educational and occupational background of parents, their household structure, risk behaviors, visions of the future, self-esteem, and health status. Students were also asked to nominate their five best male and female friends. They reported on frequency of contacts with friends and the sports and extracurricular activities that they participated in during the school year. School administrators also completed a half-hour selfadministered questionnaire in the first and third years of the study.

For the second stage of data collection (the wave 1 in-home survey), Add Health obtained rosters of all enrolled students in each school. From the union of students on school rosters and students not on a roster who completed an in-school questionnaire, Add Health randomly selected a sample for a 90-minute in-home interview. Students who did not participate in the in-school survey were eligible to be selected for participation in the in-home main sample. Consequently, the wave 1 sample includes students who did not participate in the in-school survey as well as students who had dropped out of school. Add Health completed 20,745 wave 1 in-home interviews, with an $80 \%$ response rate. Parental interviews are available for slightly more than $85 \%$ of all adolescents in the in-home sample.

Data collected during the in-home phase of Add Health provide measurement on more sensitive health risk behaviors, such as drug and alcohol use, sexual behavior, and criminal activities in addition to detailed measurement of the student's health status, health utilization, peer networks, decision making, family dynamics, aspirations, and attitudes. In addition, Add Health collected detailed data on romantic partnerships, including but not limited to the sequence of activities with partnerships and the

\footnotetext{
${ }^{16}$ The discussion is complicated by the fact that some schools are $\mathrm{K}-12$, therefore counting as a single school pair. Add Health provides data on 80 school pairs and 148 (not 160) unique schools. We lose data on 7 schools. For more detail on the Add Health design, see Bearman, Jones, and Udry (1997) and Udry and Bearman (1998).
} 
structure of romantic and sexual networks. The adolescent in-home interview was conducted using ACASI technology for all sensitive health status and health risk behavior questions. Adolescents listened to questions through earphones and directly entered their responses into a laptop computer, thereby eliminating any potential for interviewer or parental effects on their responses. ACASI technology has been shown to reduce response bias associated with sensitive questions and nonnormative behavioral items (Turner et al. 1998).

The first wave of in-home interviews was initiated in May 1995 and completed in December 1995. Most interviews were conducted during the summer. Follow-up interviews (wave 2) with adolescents who participated in the first wave of the in-home survey were conducted between April and September 1996. Interviews were not attempted with wave 1 seniors in wave 2 . Over $85 \%$ of all eligible wave 1 respondents participated in wave 2 , resulting in 14,787 interviews.

The analyses reported in this article make use of data from both inhome waves, the in-school interview, the parent interview, and school administrator surveys. School and network information comes from the in-school survey; all measures of adolescents' and parents' characteristics and attitudes are derived from the wave 1 in-home interview and parental questionnaire; and information on the timing of sexual initiation and romantic involvement is taken from both waves of in-home interviews. ${ }^{17}$

\section{MEASUREMENT}

The focus of this analysis is the effect of taking an abstinence pledge on the transition to first intercourse. Adolescents who were not married at the time of the first in-home interview were asked whether they had "ever taken a public or written pledge to remain a virgin until marriage." In the following, we first describe social demographic variables, then turn to family and individual factors. Many of the contextual variables we use in this analysis are new or less commonly found in the literature. Specifically, we explore network correlates (popularity and isolation), the characteristics of romantic partnerships (their emotional closeness and their social embeddedness), and school context. We describe these variables below. Appendix C offers more detail.

As noted earlier, differences between the transition behavior of white and black adolescents are well documented in the literature (e.g., AGI 1994; Brewster 1994; Furstenberg, Brooks-Gunn, and Morgan 1987).

\footnotetext{
${ }^{17}$ See Bearman et al. (1997) for a detailed description of the Add Health design and instrumentation.
} 
Therefore, we stratify the analysis by race and test for gender interactions within each group ${ }^{18}$ Hispanic and Asian respondents are included with the white sample and identified with a dummy variable. We measure SES as a composite index of parents' education and occupation, combining information from in-home adolescent and parental questionnaires.

Family type is measured in three categories: adolescents living with both biological parents (comparison category); adolescents living only with their mother or father; and adolescents living with two adults one or both of whom are step- or foster parents. We control for perceived parental attitudes toward sex. To measure closeness to parents, we constructed an index from three questions $\left(\alpha=.87\right.$; see app. C for exact wording). ${ }^{19}$

Sexual debut is generally conditional on interest in and ability to have sex, both of which are associated with physical maturation and puberty. In this analysis, we make use of data on self-reported physical development. Specifically, we use an index constructed from the mean of three items $(\alpha=.65)$. Girls were asked about breast and body development, boys about facial and body hair growth. Both were asked whether they looked younger, about the same, or older then adolescents in their age/ sex group..$^{20}$ As an indicator for psychological well-being, we use a scale of self-esteem constructed from the 11 items reported in appendix C $(\alpha=.86)$ and rated on a Likert scale. Cognitive ability is measured with the Add Health PPVT (Peabody Picture Verbal Test; referred to hereafter as "Add Health verbal test score"). In previous research adolescents with greater cognitive skills have been found to delay intercourse (Hofferth 1987; Halpern et al. 2000). There is some indication that the relationship between IQ and sex is curvilinear (Halpern et al. 2000; Bearman and Brückner 1999). We test this hypothesis and find little support for it with respect to either pledging or age of first sex. In addition, we control for grade point average (GPA) as an indicator for academic orientation and achievement.

Adolescents' religiosity is measured with three behavioral items $(\alpha=$ .85 ; see app. $\mathrm{C}$ for wording): frequency of praying, church attendance,

${ }^{18}$ Black respondents are defined as those who either reported only "African-American" as their racial background or reported some other racial background but gave "AfricanAmerican" as their main background.

${ }^{19}$ We explored an array of factors associated with parental supervision, including but not limited to time with parents, parent attitudes toward sex, parental supervision, perceived autonomy of decision making, and the number of dinners with parents each week. None of these variables are significant, consequently the final models we report do not include them.

${ }^{20}$ Add Health also asked about age at menarche. One could imagine using this as a measure of physical development for females, but the correlation with the other items was low, and the index performed better in the multivariate models than the age at menarche variable. Also, there is no equivalent measure for boys. 
and importance of religion. ${ }^{21}$ School attachment is constructed by taking the mean of five responses to questions measuring closeness to others at school, sense of belonging to the school community, and getting along with other students and teachers (see app. C). Participation in school sports activities is measured by a count of the activities in which an adolescent takes part.

\section{NETWORK, PARTNERSHIP, AND SCHOOL CONTEXT VARIABLES}

A simple measure of how popular adolescents are is, in degree, the number of nominations as friends (including romantic partners) they receive from others in their school. Because we need data on complete social networks to calculate in degree, this information is taken from the self-administered in-school survey. Unpopular, socially isolated teens may be both less attractive and lacking opportunity to recruit romantic partners among their friends and friends' friends. Since the distribution of the number of nominations is highly skewed, we constructed a dummy variable indicating unpopular teens. ${ }^{22}$

The in-home surveys contain a wealth of information about adolescents' romantic relationships. For the 18 months before the first in-home interview, Add Health provides full retrospective information on start and end dates of relationships as well as a description of the behaviors occurring in each relationship. ${ }^{23}$ In order to make full use of this information we construct four time-varying variables from the relationship questions. A dummy variable indicating whether or not the respondent is currently in a romantic relationship and a count of how many romantic relationships the respondent has had (including the current relationship) serve as mea-

\footnotetext{
${ }^{21}$ We also introduced a measure of parents' religiosity using the same items from the parental questionnaire. Because this variable did not add anything to the model but created additional problems with missing data, we dropped it from the analysis reported below. In addition, we controlled for religious denomination (Roman Catholic, black Protestant, moderate Protestant, pledge supporters Protestant, other denomination, none). Since the resulting five-dummy variables did not contribute to the model after controlling for the behavioral measure, and, in particular, did not modify the impact of pledging, below we report only the estimates for religiosity for the sake of brevity.

${ }^{22}$ Highly popular adolescents are not different in their transition behavior than those with average popularity (results not shown; see also Bearman and Brückner 1999).

${ }^{23}$ For the purpose of this analysis, we combine information on romantic and "like" relationships. For the former, the associated name generator was, "In the last 18 months ... have you had a special romantic relationship with anyone?" For the latter, the survey asked whether the adolescent had done each of the following three things with the same person (excluding family members): holding hands, kissing someone on the mouth, and telling him or her "that you liked or loved them."
} 
sures of exposure. The nature of the relationship is measured with two indexes. Social embeddedness of the relationship is constructed from three items asking about the occurrence of specific social events: going out together in a group, meeting each other's parents, and telling others about the relationship (see app. C for the exact wording). We expect social embeddedness to delay the onset of sexual activity in the relationship, since embedded relationships are more visible to parents and peers and thus more subject to social control. Emotional commitment combines the following events: going out alone with one's partner, seeing less of friends, thinking about oneself as a couple, giving each other presents, and saying "I love you" to each other (see app. A). We expect emotional commitment to increase the likelihood for initiating intercourse (Martin 1996; Thompson 1995).

One central concern of this article is how the effect of pledging is mediated by adolescents' social context. We subsequently show that the effect of an individual adolescent's pledge on his or her transition to first intercourse depends on the prevalence of pledging in his or her school. The effects of pledging depend on the extent to which dating relationships are confined to the school itself. Where the social environment beyond the school context provides ample opportunity for romantic involvement, the school context is likely to matter less than in schools where romantic partnerships are largely limited to the school. We therefore define socially closed schools as schools where the overwhelming majority of adolescents' friendships are within school. For each school, we calculated the ratio of opposite-sex friendship and romantic ties sent to other students in the same school over the total number of ties sent by students in the school. ${ }^{24}$ As an indicator for social closure we use a cutoff point of $83 \%$ within school friendship and romantic partnership ties. This corresponds to the sixty-fifth percentile of the distribution of within school ties over all ties. In order to explore these context effects we introduce interaction effects between pledging, proportion of female/male pledgers in the school, and social closure. ${ }^{25}$

\footnotetext{
${ }^{24}$ We tested both the overall friendship pattern and only the opposite-sex friendship pattern for schools $(r=.49)$. Both specifications yield the same results. We report the results obtained when using the opposite-sex friendship.

${ }^{25}$ The distribution when using persons as unit of analysis corresponds very closely to that obtained when using schools as unit of analysis, that is, socially closed schools comprise about $30 \%$ of our schools $(N=44)$ and $30 \%$ of our adolescents. The results are not sensitive to choosing any particular cutoff above the median. We explore as well a whole array of other school context variables, including but not limited to, school type, centrality of pledgers in school, relative density of school, school size, and the interaction of school type, individual religiosity, and school religiosity. These variables are not significant, and we have trimmed them in the final models we present.
} 
We explore a whole array of items that measure adolescent attitudes toward sex, including but not limited to indexes that capture positive (it would help me relax, feel pleasure, be less lonely, gain the respect of my partner) and negative (I would feel guilty, it would upset my mother, I would lose my partner's respect) motivations to have sex. These variables do not affect the results we report and are not included in the final trimmed models because they are available only for respondents 15 years old and older. Finally, we explored a set of measures that capture adolescent engagement with nonnormative behaviors, including delinquency, drinking, and trouble in school with teachers and peers. ${ }^{26}$

\section{MODELS}

We estimate a hazard rate model, modeling the duration from age at the wave 1 interview to first sexual intercourse. Data for respondents who never had sex are censored at the time of the second in-home interview. For this kind of problem, where we have both right censoring (the event has not yet occurred) and time varying covariates, event history methods are appropriate.

There are reasons to assume that the transition rate will not be constant over time even when controlling for all kinds of factors affecting the transition to first intercourse. A flexible approach to this time dependence of a rate is provided by a piecewise constant model with time periods (Blossfeld and Rohwer 1995). In this model, the process time axis (age) is divided into periods. The rate may change between periods but is assumed to be constant within each period. Formally, the rate from the origin state $j$ to the destination state $k$ is defined as follows:

$$
r_{j k}(t)=\exp \left[\alpha_{1}^{(j k)}+\mathbf{A}^{(j k)} \boldsymbol{\beta}^{(j k)}\right] \quad \text { if } t \in I_{1},
$$

where $\alpha^{(j k)}$ is a constant coefficient for the $l$ th time period, $\mathbf{A}^{(j k)}$ is a vector of covariates, and $\beta^{(j k)}$ is an associated vector of coefficients (Blossfeld and Rohwer 1995, p. 111). The coefficients for the time periods express the baseline rate (comparable to an intercept in a regression model), while the covariates shift the baseline rate upward or downward. ${ }^{27}$ The effect of the covariates on the rate is assumed to be proportional over time in this type of model. That means that the effect of the covariates in relative

\footnotetext{
${ }^{26}$ These measure do not affect the final results and are left out of the models we report. In general, engagement in the adolescent subculture at low levels (a little drinking, a little partying) is protective against early intercourse, since it is associated with greater connections to the peer world.

${ }^{27}$ This model is equivalent to a logistic regression with person-months as unit of analysis.
} 
terms is assumed to be constant over the course of adolescence, while the "baseline" rate is allowed to change over time. The division of the time axis into periods is arbitrary to some extent. The strategy we followed is to make the periods as small as possible while assuring that there are enough events (i.e., transitions) in each period to obtain stable and robust estimates for the rate. An extension of this basic model, the piecewise constant exponential model with period-specific effects, allows us to test the proportionality assumption by estimating a time-period-specific coefficient for each of the independent variables in the model.

In addition to right censoring, we also have to take left truncation into account, since we lose all respondents who already had sex by the time of the wave 1 interview. One solution to left truncation, which is easily implemented with the kind of model we will estimate, is to let the risk period for each person begin at the age they were interviewed for the first time (a detailed explanation and alternative solutions can be found in Guo [1993])..$^{28}$

Values for the time-varying relationship covariates are introduced in the model by means of episode splitting (Blossfeld and Rohwer 1995). Initially, each respondent contributes one episode from birth to first sex or interview date. When the values of time-dependent covariates change, the episode is split into two subepisodes. The first subepisode is assigned the start value of the covariate and is coded as right censored, while the second subepisode is assigned the new value of the time-varying covariate and the appropriate destination state.

\section{RESULTS}

Tables 2 and 3 provide basic descriptive information about the variables used in the analysis by sex, race, and pledge status. On the bivariate level, we find a number of similarities and differences between pledgers and others. For all groups, except for black females (table 3), perceived parental disapproval of sex is higher for pledgers than for nonpledgers. Except for black males, pledgers are also closer to their parents than nonpledgers. Pledgers have lower verbal test scores than others (except for black females) but, for black females and nonblack males only, higher GPA, higher school attachment, and higher self-esteem. Female pledgers in the nonblack group (table 2) come from families with lower SES than others, and their romantic relationships tend to be more embedded in their peer groups. In all groups, pledgers are significantly more religious

\footnotetext{
${ }^{28}$ The survivor functions in app. A, fig. A2, for the restricted sample are based on this correction for left truncation.
} 
TABLE 2

Descriptive Statistics on White, Asian, and Hispanic Pledgers and Nonpledgers

\begin{tabular}{|c|c|c|c|c|c|c|c|c|}
\hline & \multicolumn{4}{|c|}{ Females } & \multicolumn{4}{|c|}{ MALES } \\
\hline & \multicolumn{2}{|c|}{ With Pledge } & \multicolumn{2}{|c|}{ Without Pledge } & \multicolumn{2}{|c|}{ With Pledge } & \multicolumn{2}{|c|}{ Without Pledge } \\
\hline & Mean & $\mathrm{SD}$ & Mean & $\mathrm{SD}$ & Mean & $\mathrm{SD}$ & Mean & $\mathrm{SD}$ \\
\hline Hispanic & .25 & .43 & .19 & .39 & .20 & .40 & .16 & .37 \\
\hline Asian & .10 & .29 & .09 & .28 & .14 & .35 & .11 & .31 \\
\hline Single-parent family ${ }^{a}$ & .18 & .38 & .17 & .38 & .14 & .34 & .16 & .37 \\
\hline Step- or foster family ${ }^{a}$ & .15 & .36 & .18 & .38 & .16 & .37 & .18 & .39 \\
\hline $\operatorname{SES}^{\mathrm{a}} \ldots \ldots \ldots \ldots \ldots \ldots \ldots$ & $5.95^{*}$ & 2.60 & 6.17 & 2.55 & 6.46 & 2.58 & 6.29 & 2.47 \\
\hline Closeness to parents $^{\mathrm{a}}$. & $4.44^{*}$ & .59 & 4.39 & .59 & $4.52^{*}$ & .51 & 4.45 & .52 \\
\hline Perceived parental disapproval ${ }^{\mathrm{a}}$ & $3.83^{*}$ & .46 & 3.72 & .60 & $3.65^{*}$ & .72 & 3.47 & .77 \\
\hline In romantic relationship ${ }^{c}$ & .36 & .48 & .34 & .47 & .30 & .46 & .27 & .44 \\
\hline$N$ romantic partners ${ }^{\mathrm{c}} \ldots$ & .88 & 1.19 & .87 & 1.20 & .76 & 1.15 & .70 & 1.11 \\
\hline Emotional commitment ${ }^{\mathrm{c}}$ & 1.30 & 1.92 & 1.17 & 1.82 & 1.08 & 1.84 & .93 & 1.72 \\
\hline Embeddedness in peer group ${ }^{c} \ldots \ldots \ldots \ldots \ldots \ldots \ldots$ & $.90^{*}$ & 1.30 & .79 & 1.22 & .71 & 1.20 & .60 & 1.12 \\
\hline School attachment ${ }^{\mathrm{a}} \ldots \ldots \ldots \ldots$ & 2.89 & .69 & 2.85 & .67 & $2.92^{*}$ & .72 & 2.82 & .67 \\
\hline Unpopular in school network ${ }^{\mathrm{b}}$ & .22 & .42 & .21 & .41 & .25 & .43 & .29 & .45 \\
\hline Pubertal development $^{a} \ldots \ldots \ldots$ & 3.17 & .82 & 3.18 & .81 & 2.74 & .71 & 2.73 & .70 \\
\hline Add Health verbal test score ${ }^{a}$ & $99.71^{*}$ & 15.67 & 102.79 & 14.44 & $102.22^{*}$ & 15.00 & 105.17 & 13.77 \\
\hline $\mathrm{GPA}^{\mathrm{a}} \ldots \ldots \ldots \ldots \ldots \ldots \ldots \ldots$ & 3.10 & .74 & 3.09 & .72 & $3.01^{*}$ & .75 & 2.88 & .75 \\
\hline School sports participation ${ }^{\mathrm{b}}$ & $.91^{*}$ & .95 & 1.02 & 1.04 & 1.22 & 1.07 & 1.25 & 1.08 \\
\hline 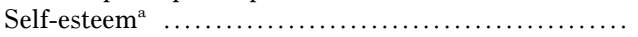 & 3.02 & .53 & 2.98 & .54 & $3.25^{*}$ & .49 & 3.14 & .50 \\
\hline (2. & $2.44^{*}$ & .80 & 1.92 & 1.00 & $2.44^{*}$ & .80 & 1.76 & 1.03 \\
\hline$\%$ pledgers ${ }^{\mathrm{a}}$ & \multirow{2}{*}{\multicolumn{2}{|c|}{703}} & \multirow{2}{*}{\multicolumn{2}{|c|}{2,351}} & \multirow{2}{*}{\multicolumn{4}{|c|}{16.6}} \\
\hline 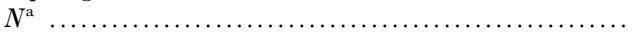 & & & & & & & & \\
\hline
\end{tabular}

${ }^{a}$ Measured at time of wave 1 , in-home interview.

${ }^{b}$ Measured at time of in-school interview.

chersation window

* Significant difference between pledgers and others (within group) in distribution ( $t$-test for metric variables; $\chi^{2}$ test for dummy variables). 
TABLE 3

Descriptive Statistics on Black Pledgers and Nonpledgers

\begin{tabular}{|c|c|c|c|c|c|c|c|c|}
\hline & \multicolumn{4}{|c|}{ FEMALES } & \multicolumn{4}{|c|}{ MALES } \\
\hline & \multicolumn{2}{|c|}{ With Pledge } & \multicolumn{2}{|c|}{ Without Pledge } & \multicolumn{2}{|c|}{ With Pledge } & \multicolumn{2}{|c|}{ Without Pledge } \\
\hline & Mean & $\mathrm{SD}$ & Mean & $\mathrm{SD}$ & Mean & $\mathrm{SD}$ & Mean & $\mathrm{SD}$ \\
\hline Single-parent family ${ }^{\mathrm{a}}$ & .38 & .49 & .45 & .50 & .37 & .49 & .34 & .47 \\
\hline Step- or foster family & .22 & .42 & .16 & .37 & .17 & .38 & .21 & .40 \\
\hline SES $^{\mathrm{a}} \quad \ldots \ldots \ldots \ldots \ldots \ldots$ & 6.03 & 2.75 & 5.97 & 2.82 & 6.62 & 2.28 & 6.39 & 2.44 \\
\hline Closeness to parents ${ }^{a}$ & $4.52^{*}$ & .53 & 4.41 & .60 & 4.63 & .41 & 4.55 & .50 \\
\hline Perceived parental disapproval $^{a}$ & 3.72 & .69 & 3.68 & .64 & $3.62^{*}$ & .78 & 3.36 & .87 \\
\hline In romantic relationship ${ }^{c} \ldots \ldots$. & .37 & .48 & .34 & .48 & .23 & .42 & .21 & .40 \\
\hline$N$ romantic partners ${ }^{\mathrm{c}}$. & .73 & 1.08 & .76 & 1.14 & .45 & .69 & .47 & .88 \\
\hline Emotional commitment ${ }^{\mathrm{c}}$ & 1.35 & 1.89 & 1.12 & 1.75 & .95 & 1.80 & .75 & 1.61 \\
\hline Embeddedness in peer group ${ }^{c}$ & .87 & 1.26 & .74 & 1.16 & .54 & 1.08 & .42 & .94 \\
\hline School attachment ${ }^{\mathrm{a}}{ }^{2} \ldots \ldots \ldots \ldots$ & $2.81^{*}$ & .71 & 2.62 & .76 & 2.85 & .77 & 2.79 & .67 \\
\hline Unpopular in school network & .30 & .46 & .29 & .45 & .38 & .49 & .33 & .47 \\
\hline Pubertal development ${ }^{\mathrm{a}} \ldots \ldots \ldots$ & 3.07 & .95 & 3.14 & .89 & 2.44 & .66 & 2.48 & .69 \\
\hline Add Health verbal test score ${ }^{\mathrm{a}}$ & 95.05 & 12.93 & 95.21 & 14.53 & $92.63^{*}$ & 17.72 & 97.89 & 15.07 \\
\hline $\mathrm{GPA}^{\mathrm{b}} \ldots \ldots \ldots \ldots \ldots \ldots \ldots \ldots \ldots$ & $2.93^{*}$ & .64 & 2.82 & .69 & 2.61 & .79 & 2.66 & .72 \\
\hline School sports participation ${ }^{\mathrm{b}}$ & .77 & .95 & .82 & 1.04 & 1.10 & 1.03 & 1.07 & 1.04 \\
\hline Self-esteem ${ }^{\mathrm{a}}$................. & $3.16^{*}$ & .57 & 3.07 & .51 & 3.31 & .48 & 3.23 & .48 \\
\hline Religiosity $^{\mathrm{a}}$ & $2.50^{*}$ & .84 & 2.23 & .95 & $2.61^{*}$ & .65 & 2.06 & 1.03 \\
\hline$\%$ pledgers ${ }^{a}$ & \multirow{2}{*}{\multicolumn{2}{|c|}{207}} & \multirow{2}{*}{\multicolumn{2}{|c|}{403}} & \multicolumn{4}{|c|}{16.8} \\
\hline & & & & & & & & \\
\hline
\end{tabular}

${ }^{a}$ Measured at time of wave 1, in-home interview.

Measured at time of in-school interview.

for start of observation window.

* Signficant difference between pledgers and others (within group) in distribution ( $t$-test for metric variables; $\chi^{2}$-test for dummy variables). 
than others. In a bivariate context, it is clear that pledgers come from more normative backgrounds than nonpledgers. Compared to nonpledgers, pledgers think their parents like them better. They may not be as smart. Bivariate differences between pledgers and others in age at sexual debut are discussed in appendix A.

\section{MULTIVARIATE ANALYSIS}

We turn now to the multivariate analysis of the transition to first intercourse. The goal is to test whether the differences between pledgers and others account for pledgers delayed sexual initiation (see app. A), or whether there is an effect of pledging that is independent of other characteristics of pledgers. A baseline model is reported in table 4. We then test gender interaction effects across both groups (tables 5 and 6). We then introduce the school context effect (model 2 in tables 7 and 8) and ask whether the estimated effects are stable across time as assumed in our basic model (tables 9 and 10). In tables 5-10 we report the results in terms of relative risk of experiencing the transition. Coefficients that express the effect of independent variables on the baseline transition rate in proportional hazard models, are often denoted as, and calculated as, $\exp (\beta)$. The number corresponding to $[\exp (\beta)-1] \times 100$ provides the expected percentage change of the baseline rate given a one-unit change in the associated covariate, other variables being equal. For an easier interpretation of the results, we report estimated $\exp (\beta)$ and the associated $95 \%$ confidence interval. For variables with confidence intervals that include 1 , we cannot reject the null hypothesis. For interaction effects for which we have specific hypotheses about the direction of the effect, we use a one-tailed significance test and report the associated $90 \%$ confidence interval. The relative risk for nonblack pledgers of 0.66 reported in table 4 , for example, means that for this group, the baseline rate is reduced by $34 \%-(0.66-1) \times 100$ - for pledgers compared to others, other things being equal.

In table 4, we report the results for the hazard model for white, Asian, and Hispanic respondents. The time (age) axis is split into 11 periods of six months each, except for the first and last period, which, due to the small number of events, are longer. In this model, adolescent females are seen to transition at the same rate as males. Hispanic respondents are not different from whites. Asians' risk of sexual initiation is about 33\% lower than that of whites. Adolescents living with single parents or in step- or foster families have a higher risk of sexual debut than those living in families with two biological parents (27\% and $24 \%$, respectively). As in previous research, higher SES decreases the risk of sexual debut. 
TABLE 4

Baseline Model for the Transition to First Intercourse

\begin{tabular}{|c|c|c|c|c|}
\hline & \multicolumn{2}{|c|}{$\begin{array}{c}\text { White, Asian, } \\
\text { Hispanic }\end{array}$} & \multicolumn{2}{|c|}{ BLACK } \\
\hline & Relative Risk & $95 \% \mathrm{CI}$ & Relative Risk & $95 \% \mathrm{CI}$ \\
\hline \multicolumn{5}{|l|}{ Age (years): } \\
\hline 12.5 up to 14 & $.03^{* * *}$ & $.01-.07$ & $.07^{* *}$ & $.01-.58$ \\
\hline 14 up to $14.5 \ldots$. & $.05^{\text {*** }}$ & $.02-.14$ & & \\
\hline 14.5 up to $15 \ldots$ & $.07^{* * *}$ & $.02-.18$ & $.09^{* * *}$ & $.01-.67$ \\
\hline 15 up to $15.5 \ldots \ldots$ & $.05^{* *}$ & $.02-.14$ & & \\
\hline 15.5 up to 16. & $.07^{* *}$ & $.02-.18$ & $.11^{* *}$ & $.01-.83$ \\
\hline 16 up to 16.5 & $.08^{* *}$ & $.03-.20$ & & \\
\hline 16.5 up to $17 \ldots \ldots \ldots \ldots \ldots \ldots$ & $.06^{* *}$ & $.02-.16$ & & \\
\hline 17 up to $17.5 \ldots \ldots \ldots \ldots \ldots \ldots$ & $.08^{* *}$ & $.03-.22$ & & \\
\hline 17.5 up to $18 \ldots \ldots \ldots \ldots \ldots \ldots$ & $.10^{* *}$ & $.04-.27$ & .14 & $.02-1.06$ \\
\hline 18 up to $18.5 \ldots \ldots \ldots \ldots \ldots \ldots$ & $.11^{* *}$ & $.04-.28$ & & \\
\hline 18.5 and older $\ldots \ldots \ldots \ldots \ldots \ldots$ & $.10^{* *}$ & $.04-.27$ & & \\
\hline Female $\ldots \ldots \ldots \ldots \ldots \ldots \ldots \ldots$ & 1.18 & $.99-1.41$ & .83 & $.56-1.23$ \\
\hline Hispanic $\ldots \ldots \ldots \ldots \ldots \ldots \ldots \ldots$ & .97 & $.79-1.19$ & & \\
\hline Asian & $.67^{* *}$ & $.46-.96$ & & \\
\hline Single-parent family & $1.27^{* *}$ & $1.04-1.55$ & 1.30 & $.88-1.91$ \\
\hline Step- or foster family & $1.24^{* *}$ & $1.02-1.50$ & 1.28 & $.81-2.02$ \\
\hline SES $\ldots \ldots \ldots \ldots \ldots \ldots \ldots$ & $.95^{* *}$ & $.92-.99$ & .98 & $.91-1.05$ \\
\hline Closeness to parents & .90 & $.78-1.03$ & .86 & $.65-1.16$ \\
\hline Perceived parental disapproval ... & $.80^{* *}$ & $.73-.88$ & .93 & $.75-1.16$ \\
\hline In romantic relationship $\ldots \ldots \ldots \ldots$ & $3.31^{* *}$ & $2.36-4.63$ & $3.69^{* * *}$ & $1.88-7.26$ \\
\hline$N$ romantic partners & $1.16^{* *}$ & $1.08-1.23$ & 1.07 & $.89-1.27$ \\
\hline Emotional commitment & $1.14^{* *}$ & $1.05-1.24$ & .92 & $.77-1.10$ \\
\hline Embeddedness in peer group ..... & .92 & $.82-1.04$ & 1.01 & $.77-1.31$ \\
\hline School attachment & $.83^{* *}$ & $.74-.93$ & 1.05 & $.82-1.35$ \\
\hline Unpopular in school network ..... & $.81^{* *}$ & $.66-.99$ & .71 & $.49-1.05$ \\
\hline Pubertal development & $1.16^{* *}$ & $1.04-1.29$ & 1.02 & $.83-1.24$ \\
\hline Add Health verbal test score ..... & 1.00 & $.99-1.00$ & .99 & $.98-1.01$ \\
\hline GPA & $.89^{* *}$ & $.79-.99$ & $.77^{* *}$ & $.60-.99$ \\
\hline School sports participation ......... & .93 & $.86-1.01$ & 1.08 & $.93-1.25$ \\
\hline Self-esteem $\ldots \ldots \ldots \ldots \ldots \ldots \ldots$ & 1.06 & $.90-1.25$ & .96 & $.66-1.40$ \\
\hline Religiosity $\ldots \ldots \ldots \ldots+\ldots \ldots$ & $.84^{* *}$ & $.78-.91$ & .88 & $.75-1.04$ \\
\hline Pledge $\ldots \ldots \ldots \ldots$ & $.66^{* * *}$ & $.52-.83$ & 1.04 & $.70-1.07$ \\
\hline
\end{tabular}

NotE. $-N$ of cases $=5,679$ for nonblacks and 997 for blacks. $N$ of events $=690$ for nonblacks and 152 for blacks. $\chi^{2}(d f)$ is $455(40)$ for nonblacks and $48(27)$ for blacks. $\mathrm{CI}=$ confidence interval. Coefficients for missing data flags are omitted.

* $P \leq .01$, two-tailed test.

*** $P \leq .05$. 
Closeness to parents has the expected direction, but is not significant in this model, while perceived parental disapproval of sexual activity decreases the relative risk by $20 \%$ for each unit change on the five-point scale. Adolescents in romantic relationships are more than twice as likely to experience intercourse, and exposure through previous dating relationships increases risk of sexual debut by about $16 \%$ for each additional previous romantic partner. Emotional commitment in the current relationship increases the relative risk by $14 \%$ for each unit change on the five- point scale, while embeddedness of the relationship is not significant. Higher school attachment and higher grades decrease the risk substantially, as expected, while participation in school sports and self-esteem are not significant. Socially unpopular adolescents are less likely to have intercourse, while adolescents that are more physically mature than their peers are more likely to have intercourse. Higher religiosity decreases the risk of sexual debut.

Pledging decreases the risk of intercourse substantially and independently. Pledgers' relative risk of sexual initiation is estimated to be $34 \%$ lower than nonpledgers, even after controlling for a wide range of personal characteristics, religiosity, and other protective factors. This is the main pledge effect. It is robust to model specification. And it is observed even when the main correlates of pledging (see app. B) are in the model ${ }^{29} \mathrm{We}$ discuss the pledge effect further below.

\section{GENDER INTERACTION EFFECTS}

We first discuss the results for nonblack adolescents (table 5). ${ }^{30}$ In contrast to our expectations, family type and normative parental influences are not different for boys than for girls. While most interactions have the

\footnotetext{
${ }^{29}$ For black adolescents (table 4) we observe few differentiating factors. The baseline time periods are fewer and longer for this sample, due to the smaller number of cases and events. The only significant factors here are being in a romantic relationship and GPA. The pledge does not make a difference.

${ }^{30}$ Table 5 reports results for main and interaction effects in two separate columns for ease of comparison; i.e., we do not estimate a separate model for males and females. The first column in table 5 reports main effects, the second column interaction effects with gender. Thus, the effect for boys can be seen in col. 1, whereas effects for girls are obtained by adding cols. 1 and 2 in each panel. The models reported in table 5 allow for gender differences in the effect of all independent variables on sexual debut, whereas the models reported in table 4 constrained the effects to be the same for boys as for girls. Please note that, for reasons of space, we omit the coefficients for the baseline rate in tables 5 and 6.
} 
American Journal of Sociology

TABLE 5

Transition to First Intercourse: Gender Interaction Effects for Whites, Asians, AND Hispanics

\begin{tabular}{|c|c|c|c|c|}
\hline \multirow[b]{2}{*}{ INDEPENDENT VARIABLES } & \multicolumn{2}{|c|}{ DiRECT EFFECTS } & \multicolumn{2}{|c|}{ GENDER INTERACTION } \\
\hline & Relative Risk & $95 \% \mathrm{CI}$ & Relative Risk & $95 \% \mathrm{CI}$ \\
\hline Female & $14.70^{* *}$ & $2.09-100.03$ & & . . \\
\hline Hispanic & $1.53^{*}$ & $1.12-2.09$ & $.47^{* *}$ & $.31-.71$ \\
\hline Asian ... & .78 & $.46-1.31$ & .75 & $.37-1.53$ \\
\hline Single-parent family & 1.37 & $1.00-1.87$ & .89 & $.60-1.33$ \\
\hline Step- or foster family $\ldots \ldots \ldots \ldots \ldots$ & $1.45^{* *}$ & $1.07-1.95$ & .76 & $.52-1.12$ \\
\hline SES $\ldots \ldots \ldots$ & 1.00 & $.95-1.06$ & $.92^{*}$ & $.86-.99$ \\
\hline Closeness to parents $\ldots \ldots \ldots \ldots \ldots$ & 1.00 & $.79-1.26$ & .86 & $.75-1.00$ \\
\hline Perceived parental disapproval ... & $.86^{* *}$ & $.75-.99$ & .91 & $.75-1.10$ \\
\hline In romantic relationship $\ldots \ldots \ldots \ldots$ & $2.54^{* *}$ & $1.51-4.28$ & 1.51 & $.76-3.01$ \\
\hline$N$ romantic partners $\ldots \ldots \ldots \ldots \ldots$ & $1.24^{* *}$ & $1.11-1.38$ & .91 & $.79-1.04$ \\
\hline Emotional commitment $\ldots \ldots \ldots$. & $1.17^{* *}$ & $1.03-1.33$ & .95 & $.81-1.12$ \\
\hline Embeddedness in peer group $\ldots .$. & .86 & $.71-1.05$ & 1.12 & $.87-1.43$ \\
\hline School attachment $\ldots \ldots \ldots \ldots \ldots$ & $.74^{* *}$ & $.63-.88$ & 1.19 & $.94-1.50$ \\
\hline Unpopular in school network ..... & .87 & $.64-1.17$ & .86 & $.58-1.27$ \\
\hline Pubertal development $\ldots . \ldots \ldots \ldots$ & $1.30^{* *}$ & $1.08-1.57$ & .86 & $.69-1.08$ \\
\hline Add Health verbal test score & 1.00 & $.99-1.01$ & 1.00 & $.99-1.01$ \\
\hline GPA $\ldots \ldots \ldots \ldots \ldots \ldots \ldots \ldots \ldots$ & $.86^{*}$ & $.72-1.02$ & 1.04 & $.83-1.30$ \\
\hline School sports participation ....... & 1.01 & $.90-1.13$ & $.86^{*}$ & $.79-.93^{\mathrm{a}}$ \\
\hline Self-esteem $\ldots \ldots \ldots \ldots \ldots \ldots \ldots$ & $1.28^{*}$ & $1.11-1.46^{\mathrm{a}}$ & $.75^{*}$ & $.63-.89^{\mathrm{a}}$ \\
\hline Religiosity .... & $.81^{* *}$ & $.72-.91$ & 1.06 & $.91-1.24$ \\
\hline Pledge $\ldots \ldots \ldots \ldots \ldots \ldots \ldots \ldots$ & $.50^{* *}$ & $.31-.80$ & 1.37 & $.80-2.35$ \\
\hline
\end{tabular}

Note. $-N$ of cases $=5,679$ (3,054 female). $N$ of events $=690$ (412 female). $\chi^{2}(d f)$ is $472(60) . \mathrm{CI}=$ confidence interval. Coefficients for baseline rate are omitted.

a $90 \%$ confidence interval.

* $P \leq .01$, one-tailed test.

** $P \leq .05$, two-tailed test.

expected direction, they do not reach significance. Higher parents' SES, however, delays intercourse only for girls, not for boys. ${ }^{31}$

Although girls report having more relationships, are more likely to be in a relationship, and report higher emotional commitment and embeddedness in the relationships they are in, romantic involvement has the same effect on both sexes. Participation in school sports is significant only for girls. Self-esteem has a positive effect on boys' sexual debut, whereas for girls, the positive effect of self-esteem is reduced to zero by the negative interaction effect.

For black respondents (table 6), the positive effect of pubertal development is greatly reduced for girls. Sports participation increases the

${ }^{31}$ For girls, higher SES may indicate a more protective environment; for boys, higher SES may provide them with useful resources for attracting adolescent females, e.g., cars (table 5). 
Virginity Pledges

TABLE 6

Transition to First Intercourse: Gender Interaction Effects for Blacks

\begin{tabular}{|c|c|c|c|c|}
\hline \multirow[b]{2}{*}{ INDEPENDENT VARIABLES } & \multicolumn{2}{|c|}{ Direct EFfECts } & \multicolumn{2}{|c|}{ GENDER INTERACTION } \\
\hline & Relative Risk & $95 \% \mathrm{CI}$ & Relative Risk & $95 \% \mathrm{CI}$ \\
\hline Female & 5.56 & $.08-393.92$ & & $\ldots$ \\
\hline Hispanic $\ldots . . . \ldots \ldots \ldots \ldots \ldots$ & & $\cdots$ & & $\ldots$ \\
\hline Asian $\ldots \ldots \ldots \ldots \ldots \ldots \ldots \ldots \ldots \ldots$ & & . & & $\ldots$ \\
\hline Single-parent family & 1.27 & $.65-2.49$ & 1.02 & $.44-2.34$ \\
\hline Step- or foster family & 1.41 & $.66-3.03$ & .96 & $.36-2.53$ \\
\hline SES $\ldots \ldots \ldots \ldots \ldots \ldots \ldots \ldots \ldots \ldots \ldots$ & 1.04 & $.91-1.19$ & .91 & $.78-1.07$ \\
\hline Closeness to parents & 1.19 & $.62-2.29$ & .64 & $.31-1.33$ \\
\hline Perceived parental disapproval ... & .94 & $.69-1.28$ & 1.01 & $.65-1.59$ \\
\hline In romantic relationship $\ldots \ldots \ldots \ldots$ & $8.80^{* *}$ & $2.48-31.15$ & .32 & $.07-1.46$ \\
\hline$N$ romantic partners $\ldots \ldots \ldots \ldots \ldots$ & .85 & $.56-1.30$ & 1.34 & $.84-2.15$ \\
\hline Emotional commitment $\ldots \ldots \ldots$ & $.72^{* *}$ & $.52-.99$ & $1.43^{*}$ & $1.17-1.75^{\mathrm{a}}$ \\
\hline Embeddedness in peer group ..... & 1.03 & $.64-1.65$ & .91 & $.51-1.63$ \\
\hline School attachment $\ldots . \ldots \ldots \ldots . . .$. & 1.04 & $.67-1.62$ & 1.03 & $.60-1.75$ \\
\hline Unpopular in school network ..... & 1.03 & $.56-1.92$ & .56 & $.26-1.20$ \\
\hline Pubertal development $\ldots . . \ldots \ldots \ldots$ & $1.42^{*}$ & $1.15-1.74^{\mathrm{a}}$ & $.66^{*}$ & $.52-.84^{\mathrm{a}}$ \\
\hline Add Health verbal test score ..... & $.98^{*}$ & $.96-1.00$ & 1.02 & $.99-1.04$ \\
\hline GPA $\ldots \ldots \ldots \ldots \ldots \ldots \ldots$ & .82 & $.55-1.21$ & .85 & $.51-1.41$ \\
\hline School sports participation ........ & $1.37^{* *}$ & $1.07-1.76$ & $.69^{* *}$ & $.50-.95$ \\
\hline Self-esteem $\ldots \ldots \ldots \ldots \ldots \ldots \ldots$ & .75 & $.40-1.44$ & 1.53 & $.69-3.38$ \\
\hline Religiosity ..... & 1.06 & $.80-1.41$ & .78 & $.55-1.11$ \\
\hline Pledge $\ldots \ldots \ldots \ldots \ldots \ldots \ldots \ldots \ldots$ & .77 & $.35-1.73$ & 1.42 & $.56-3.59$ \\
\hline
\end{tabular}

Note. $-N$ of cases $=997$ (610 female). $N$ of events $=152$ (97 female). $\chi^{2}(d f)$ is $58(45) . \mathrm{CI}=$ confidence interval. Coefficients for baseline rate are omitted.

a $90 \%$ confidence interval.

* $P \leq .05$, one-tailed test.

** $P \leq .05$, two-tailed test.

likelihood of sexual debut for boys but not for girls. The most striking result is the gender difference in terms of black adolescents' emotional commitment (see figs. 1 and 2). In contrast to all other groups, emotional commitment within a relationship decreases the transition rate for black male adolescents. One interpretation of the impact of emotional commitment on black males' sexual behavior may be a "double standard" common in populations with a large excess of females over males: that is, one does not love the women one has sex with and vice versa (Guttentag and Secord 1983). ${ }^{32}$ This finding has implications for the pledge movement, which assumes that sex is the expression of romantic love. That

${ }^{32}$ We find the same result when analyzing a more inclusive sample, starting the observation at the time-retrospective data on relationships starts, namely 18 months before the first in-home interview. However, for this sample we cannot include a large part of the protective factors included in the model reported in tables 2 and 3 since measurement occurred after we observe these relationships. 


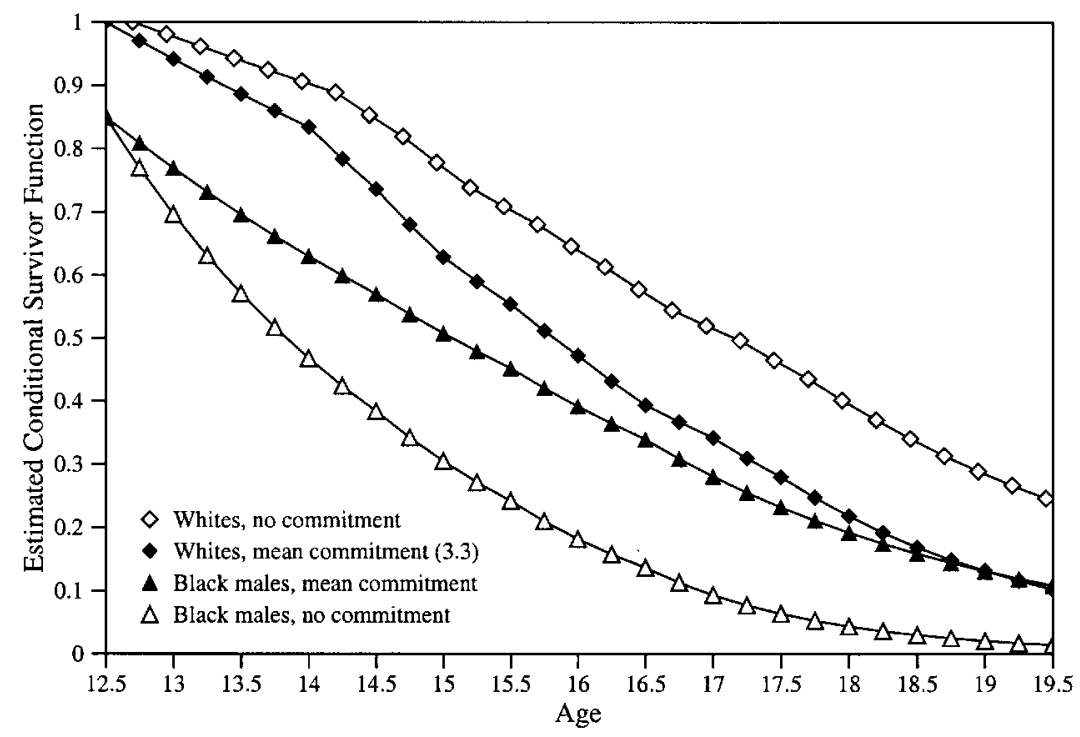

FIG. 1.-Estimated effect of emotional commitment on black males (based on results reported in table 6 below; other covariates are evaluated at means/modes).

this is not true for black males suggests one of the reasons why we cannot observe a pledge effect in our sample of that group.

In contrast to our hypotheses (see table 1), we find little evidence for gender differences in the effect of social control. Most important for this article, there are no significant gender interactions with respect to the pledge, which works for white, Hispanic, and Asian adolescent males and females in the same way. The key finding for blacks is the inversion of the role of emotional closeness in relationships observed for black males. We return to this below.

\section{THE PLEDGE EFFECT IN CONTEXT}

It is important to examine the mediating role of school context in shaping the impact of the pledge. We first report a new baseline model in table 7 (model 1) for nonblacks and table 8 (model 1) for blacks, which contains only gender interaction effects that turned out to be significant in the models reported in tables 5 and $6 .{ }^{33}$ We then add the interaction terms

\footnotetext{
${ }^{33}$ In these analyses, we include only significant gender interaction effects. Excluding nonsignificant interaction terms from the model does not reduce model fit. Including all interaction effects introduces collinearity (note that the SEs in the model for blacks are already affected by collinearity as can be seen by the huge confidence interval for
} 


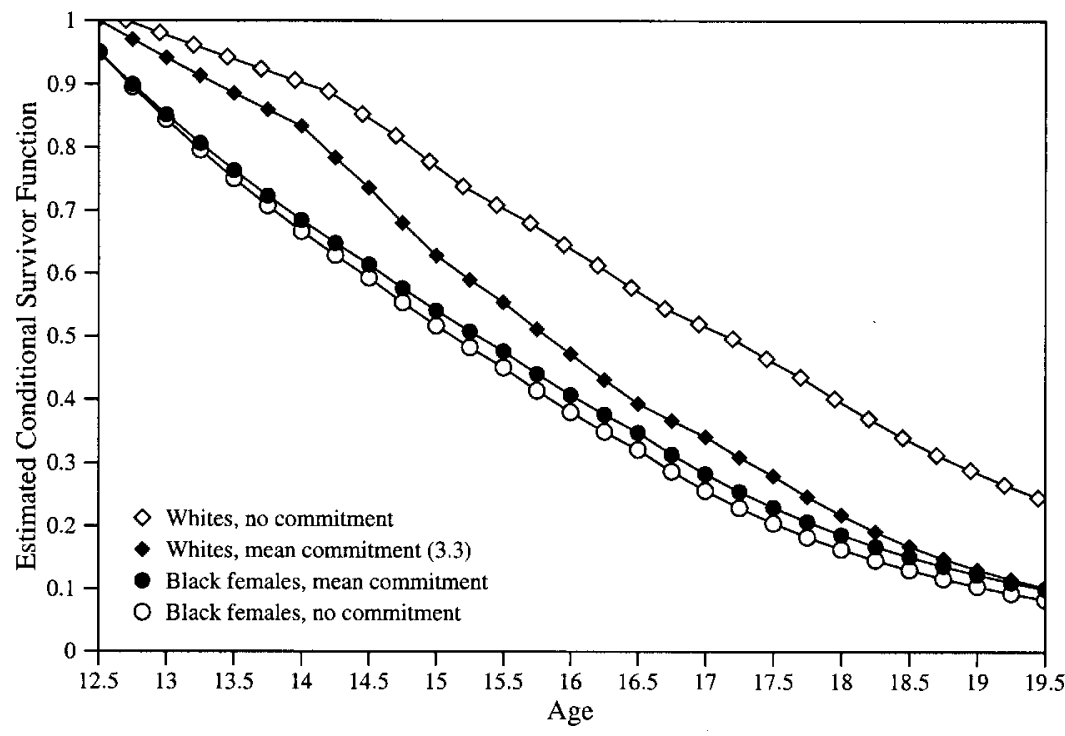

FIG. 2.-Estimated effect of emotional commitment on black females (based on results reported in table 6; other covariates are evaluated at means/modes).

described below in the second model reported in tables 7 and 8 . We first distinguish schools with respect to their providing the focus for adolescent friendship and romantic relationships. For all groups, we can observe a significant three-way interaction between pledging, social closure in the school, and \%pledgers of the same sex in the school. ${ }^{34}$ We focus the discussion on the results for nonblack adolescents (table 7, model 2). The results for blacks (table 8) are similar to those discussed below but more difficult to ascertain since the interaction terms are significant only at the .01 level. The effect is complex.

In socially open schools- that is, schools where less then $83 \%$ of friendship and romantic ties to the opposite sex are sent within the school

the coefficient for female). For reasons of space and ease of interpretation, we report only the estimates for the reduced model specification.

${ }^{34}$ Introducing only interaction effect terms for pledging and percent same-sex pledgers results in nonsignificant coefficients. The context effect of pledging thus depends on whether social relations are largely confined within the school. This result is not substantively sensitive to the cutoff point chosen for social closure, but the estimates get smaller when using a lower cutoff and greater when using a higher cutoff. We present the full interactional model in tables 7 and 8 , including the estimates for nonpledgers; when restricting the model to the context effect for pledgers only, the interaction effects yield a significant improvement of the model fit $\left(\chi^{2}=8 ; d f=3 ; P=0.04\right)$. Excluding the nonsignificant parameters does not affect the estimates for the significant interaction effect parameters. 
TABLE 7

Transition to First Intercourse: White, Asian, AND Hispanic Respondents

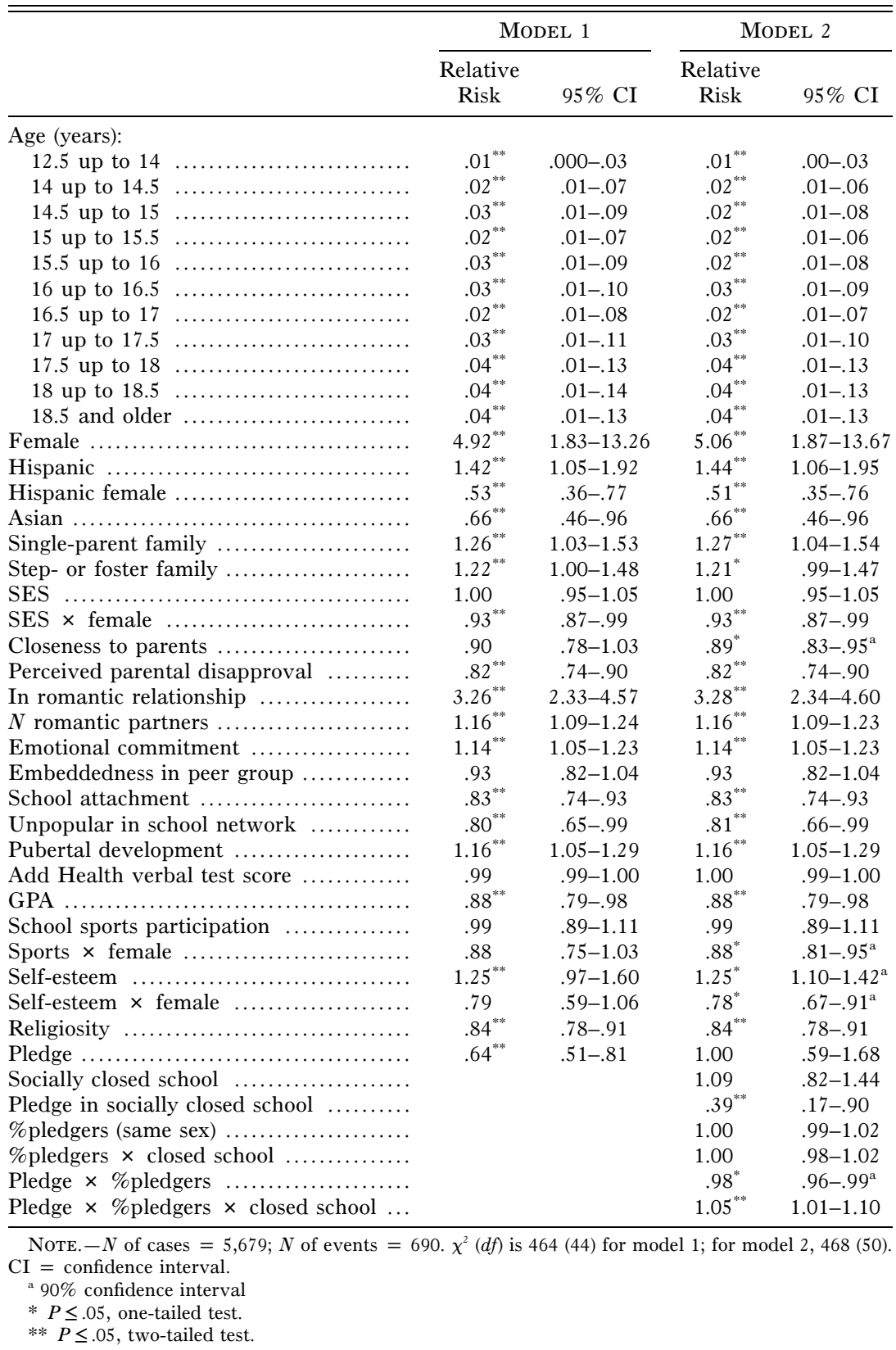


TABLE 8

Transition to First Intercourse: Black ResPondents

\begin{tabular}{|c|c|c|c|c|}
\hline & \multicolumn{2}{|c|}{ Model 1} & \multicolumn{2}{|c|}{ MODEL 2} \\
\hline & $\begin{array}{c}\text { Relative } \\
\text { Risk }\end{array}$ & $95 \% \mathrm{CI}$ & $\begin{array}{c}\text { Relative } \\
\text { Risk }\end{array}$ & $95 \% \mathrm{CI}$ \\
\hline \multicolumn{5}{|l|}{ Age: } \\
\hline 12.5 up to 14.5 & $.04^{* *}$ & $.00-.36$ & $.04^{* * *}$ & $.00-.40$ \\
\hline 14.5 up to 15.5 & $.05^{* *}$ & $.01-.41$ & $.05^{* *}$ & $.01-.46$ \\
\hline 15.5 up to 16.5 & $.06^{* *}$ & $.01-.51$ & $.06^{* *}$ & $.01-.55$ \\
\hline 16.5 and older & $.08^{* *}$ & $.01-.67$ & $.07^{* *}$ & $.01-.68$ \\
\hline Female & 1.98 & $.53-7.40$ & 2.14 & $.55-8.34$ \\
\hline Single-parent family & 1.27 & $.87-1.87$ & 1.28 & $.87-1.89$ \\
\hline Step- or foster family . & 1.30 & $.82-2.05$ & 1.28 & $.80-2.02$ \\
\hline SES & .98 & $.91-1.05$ & .97 & $.91-1.04$ \\
\hline Closeness to parents & .87 & .65-1.16 & .86 & .64-1.16 \\
\hline Perceived parental disapproval & .94 & $.75-1.18$ & .93 & $.75-1.17$ \\
\hline In romantic relationship & $3.84^{* *}$ & $1.93-7.61$ & $3.82^{* *}$ & $1.92-7.63$ \\
\hline$N$ romantic partners & 1.06 & $.89-1.27$ & 1.05 & $.88-1.27$ \\
\hline Emotional commitment & $.81^{*}$ & $.73-.91^{\mathrm{a}}$ & $.81^{*}$ & $.73-.91^{\mathrm{a}}$ \\
\hline Emotional commitment $\times$ female & $1.20^{* * *}$ & $1.00-1.44$ & $1.20^{* *}$ & $1.00-1.44$ \\
\hline Embeddedness in peer group . & .98 & $.75-1.29$ & .99 & $.75-1.30$ \\
\hline School attachment & 1.06 & $.83-1.35$ & 1.04 & $.81-1.33$ \\
\hline Unpopular in school network & $.72^{*}$ & $.59-.88^{\mathrm{a}}$ & $.71^{*}$ & $.58-.86^{\mathrm{a}}$ \\
\hline Pubertal development $\ldots \ldots \ldots \ldots \ldots \ldots \ldots$ & 1.31 & $.89-1.94$ & 1.34 & $.90-2.00$ \\
\hline Pubertal development $\times$ female & .73 & $.47-1.14$ & .70 & .45-1.11 \\
\hline Add Health verbal test score & .99 & $.98-1.01$ & .99 & $.98-1.01$ \\
\hline GPA & $.77^{* * *}$ & $.60-.99$ & $.77^{* *}$ & $.60-.99$ \\
\hline School sports participation & $1.31^{* *}$ & $1.03-1.66$ & $1.31^{* *}$ & $1.03-1.66$ \\
\hline Sports $\times$ female $\ldots \ldots \ldots \ldots$ & $.74^{* * *}$ & $.55-1.01$ & $.76^{*}$ & $.65-.89^{\mathrm{a}}$ \\
\hline Self-esteem $\quad \ldots \ldots \ldots \ldots \ldots \ldots \ldots \ldots \ldots \ldots$ & .96 & $.66-1.39$ & .96 & .66-1.39 \\
\hline Religiosity $\ldots \ldots \ldots \ldots \ldots \ldots \ldots \ldots \ldots \ldots$ & .89 & $.76-1.05$ & .90 & .76-1.06 \\
\hline Pledge $\ldots \ldots \ldots \ldots \ldots \ldots \ldots \ldots \ldots \ldots \ldots \ldots \ldots \ldots \ldots \ldots \ldots$ & 1.02 & $.69-1.52$ & 1.51 & $.57-4.00$ \\
\hline Socially closed school $\ldots \ldots \ldots \ldots \ldots \ldots$ & & & 1.79 & $.74-4.32$ \\
\hline Pledge in socially closed school $\ldots . . . \ldots \ldots$ & & & $.21^{*}$ & $.09-.51^{\mathrm{a}}$ \\
\hline \%pledgers (same sex) $\ldots \ldots \ldots \ldots \ldots \ldots \ldots$ & & & 1.01 & $.98-1.05$ \\
\hline \%pledgers $\times$ closed school $\ldots \ldots \ldots \ldots \ldots$ & & & $.94^{*}$ & $.88-1.01$ \\
\hline Pledge $\times \%$ pledgers $\ldots \ldots \ldots \ldots \ldots \ldots \ldots$ & & & .98 & $.92-1.04$ \\
\hline Pledge $\times \%$ pledgers $\times$ closed school & & & $1.10^{*}$ & $1.05-1.16^{\mathrm{a}}$ \\
\hline
\end{tabular}

Note. $-N$ of cases $=997 ; N$ of events $=152 . \chi^{2}(d f)$ for model 1 is 52 (30); for model 2, 55 (36). a $90 \%$ confidence interval.

* $P \leq .05$, one-tailed test

** $P \leq .05$, two-tailed test. 


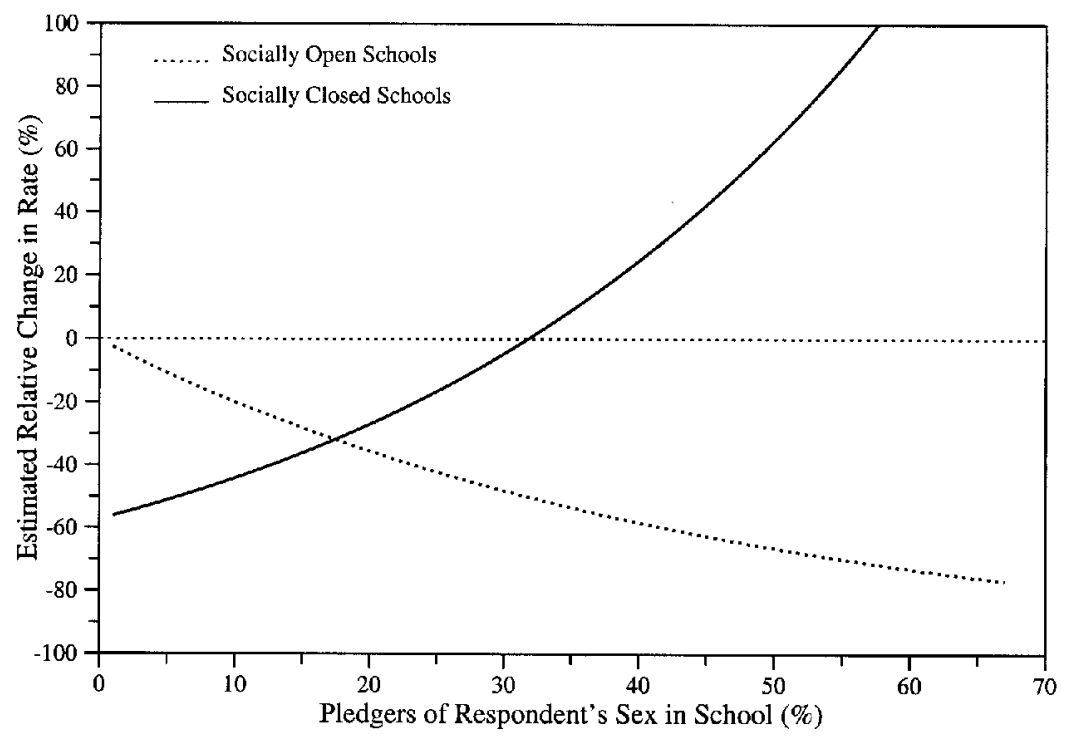

FIG. 3.-Transition rate for pledgers and context, by school type

itself-the delay effect of pledging on an individual's transition rate depends on how many other students of the same sex have pledged. Where no other pledgers were present at the time of the first in-home interview, pledgers transition at the same rate as others. In short, there is no delay effect. The more other pledgers are present in the school, however, the later pledgers initiate intercourse. Specifically, for nonblack adolescents (table 7, model 2), for every $1 \%$ additional same-sex pledgers, the rate of transition to first intercourse is delayed by $2 \%$. In socially open schools, pledging delays intercourse only if there is an interacting community of pledgers.

We call schools where the majority of cross-sex friendship and romantic relationship ties are sent to other students in the school "socially closed." For socially closed schools (30\% of the schools in our sample), where social relations are largely confined within the school, the opposite obtains. Where no other pledgers are present, pledgers are much less likely than others to experience sexual debut. Where many other pledgers are present in these schools, pledgers' transition rate is higher than that of pledgers in schools with few pledgers. These findings are illustrated in figure 3, which reports the estimated relative effect of \%pledgers on the transition rate for nonblack pledgers in both school types.

For adolescents in schools with more than $30 \%$ pledgers, the relative change in the baseline rate changes from negative to positive, indicating 
a threshold for pledging's effectiveness. ${ }^{35}$ Once the pledge becomes normative, it ceases to have an effect. The pledge identity is meaningful, consequently, only if it is a minority identity, a common situation for identity movements. ${ }^{36}$ In socially open schools, all identities can be in the minority.

The pledge movement as an identity movement and the pledge effect as an identity effect would be consistent with an empirical observation that the effect of pledging approaches zero with increasing proportion of pledgers in a school. Instead, we observe a reversal of the effect, that is, a positive effect of pledging on the hazard rate. To interpret this reversal recall that the rate is a "temporally local" dimension. ${ }^{37}$ Recall that the same dynamic appears earlier in this article as well. Early gender differences and later convergence in the survivor functions for the transition to first sex (fig. A1) necessarily translates into different estimates of the gender effect on the baseline rate depending on which ages we look at. When looking at a sample that includes early transitioners, females are expected to have a lower transition rate than males. When looking at later ages, the rate for females is higher than for males-females have to "catch up" with males in order for the proportions to converge, as they do in figure A1. In the same way, pledgers have to "catch up" with nonpledgers, resulting in a transition rate that is higher than that of nonpledgers. ${ }^{38}$

Consider by analogy two tubs of water that both have to become full (i.e., the eventual transition to first sex). If one faucet is running at full blast it fills up quickly. The other faucet runs more slowly, so at a certain time it is less full than the first. But, in order for both tubs to be full at roughly the same time, the second faucet needs to release water more quickly at some time. This faster release of water to achieve parity is the

${ }^{35}$ There are 14 schools in our sample with $30 \%$ and more pledgers (i.e., about $10 \%$ of all schools contained in this sample). These 14 schools, eight of which are socially closed schools, contribute 348 adolescents to the sample. This results in 141 adolescents in socially closed schools with $30 \%$ and more pledgers in them. Of these 141 persons, 85 are pledgers. Socially open schools with with $30 \%$ and more pledgers contribute 206 adolescents, 136 of whom are pledgers.

${ }^{36}$ The lack of a similar threshold for socially open school may simply mean that we capture more effectively the relevant social context, since the measurement of the context effect is more precise when social relations are largely taking place within the school.

${ }^{37}$ The classic illustration of this property of a rate is the comparison between the volume of water in a container (i.e., the proportion of units experiencing some event) and the speed at which the water filling the container leaves the faucet (the transition rate).

${ }^{38}$ In the next section, we test for such age dependencies of the effect of pledging and other covariates on the transition rate. 
positive effect on the baseline rate. Substantively, pledgers in schools with many pledgers would not transition to sex more quickly if they were not already delayed.

Our data are limited in a specific way: we do not observe the process of pledging in schools over time, and the data are right censored and left truncated. The best we can do with the data is to estimate a proportion of pledgers at a specific point in time and observe what happens after that. If we could operationalize context in a time-varying fashion we would most certainly observe a flattening-out of the context effect: because we could observe individuals and the movement as they grow together. ${ }^{39}$ In the data that we have, we observe teens in socially closed schools with many pledgers on the average in a phase in which they are catching up with nonpledgers. ${ }^{40}$ Note, however, that figure 3 is assuming a proportional hazard rate. What we can do is let the context effect vary across different ages. When we relax the proportional hazard assumption, we do see a decline of the school type interaction effect (see table 9). ${ }^{41}$

${ }^{39}$ We tested for nonlinearity in the context effect by breaking up the distribution in sets of dummy variables (e.g., 0 up to $15 \%, 15$ up to $30 \%, 30 \%$ up to $40 \%$ pledgers, above $40 \%$ ). We tried out different cutoffs for the groups but there was no indication that the effect turns around. The model fit did not increase, and the dummy variables indicating high percentages of pledgers were significant in interaction with school type.

${ }^{40} A J S$ reviewers also suggested we use "social closure" as a continuous variable rather than as a dummy variable with an arbitrary cutoff point and to represent the resulting three-way interaction between pledging, context, and school closure as a three-dimensional plot. Unfortunately, the distribution of the social closure measure (proportion of opposite-sex friendship ties within school) is not normally distributed (most teens are in schools with very few outside ties). In addition, the use of a continuous variable for the three-way interaction implies a linear association of social closure with the interaction effect of pledging and proportion pledgers, an assumption that does not hold in these data (see n. 22 above for the choice of a cutoff point). It was also suggested to employ a "more naturally" dichotomous school characteristic such as urban or regional characteristics as a substitute for the social closure measure. There is no oneto-one correspondence between rural settings or location and social closure, however, and it seemed preferable to use a concept that has direct bearing on the nature of the underlying sociological mechanism rather than a categorical proxy that introduces both measurement error (since there are socially open schools even in nonurban settings and in the South, for example) and conceptual ambiguity. Although characterizations of the environment such as urbanicity and region are associated with the outcomes studied in this article, in the multivariate context of the analysis shown they do not contribute to any of the models, most likely because we control for a great number of intervening variables such as individual and family characteristics.

${ }^{41}$ This is the closest that we can come to modeling the process. Reviewers suggested using the estimates of the odds of pledging obtained in the logistic regression reported in appendix B instead of the observed pledge as a covariate in the hazard models, even though these estimates would be based on a different sample. The idea is to rule out the possibility of correlated errors resulting from the fact that pledging in schools where pledging is common is in part a measure of being in such a school. In other words, the proportion of pledgers in the school would be an indicator of the extent of 
For adolescents who have not taken a pledge, in contrast, the school context effects are not significant. That is, their transition rate is not affected by the presence of pledgers in the school. This suggests that the alternative interpretation of the threshold effect we identify in socially closed schools - that once there are too many pledgers in a school, others concentrate their romantic efforts on trying to seduce pledgers since there are too few alternative outlets (a sort of opportunity argument) — cannot be accurate. If this were true, we would expect to observe an effect of the proportion of pledgers on nonpledgers. The coefficient for the effect of the prevalence of pledging on nonpledgers, however, not only lacks significance but is also very small.

The mechanisms by which the pledge operates are revealed through this contextual effect. If there are no pledgers, there is no pledge effect.

"unobserved heterogeneity" among pledgers, but only in some schools and not in others. It is a well-established finding that as a movement grows, members will be more heterogeneous with respect to their backgrounds and orientations. For the unobserved heterogeneity interpretation to be consistent with the reported results, however, social closure has to be interpreted as an indicator for heterogeneity of pledgers (albeit only when many pledgers are around). Hence, we also need to find some property of the school that accounts for both widespread pledging of heterogeneous students and a tendency for friendship ties to be organized within the school. We have tried to rule out the presence of any such property we could think of in terms of characteristics of students, parents, and schools. For example, small schools may have both more heterogeneous students (in spite of residential segregation) and be socially closed. Conversely, large schools may have a more heterogeneous but larger student body and thus could have a critical mass of homogenous pledgers and be socially open. However, socially closed schools are on the average slightly bigger than socially open schools. In addition, the school type-context interaction effect cannot be reproduced/erased with a school size-context interaction effect. But beyond this, the proposed strategy cannot work for our analyses. The reason why we used observed rather than predicted pledging in the sexual debut models is a time-ordering issue. Recall that the strongest predictors of pledging are characteristics that vary over time (being in a romantic relationship, number of partners, and, most important, proportion of pledgers in the school). Because we have no information on the timing of pledges, we cannot use these predictors for estimating the odds of pledging for adolescents in the sample used for predicting the timing of sexual debut because we do not know their values. Imagine further if one would use the current values (e.g., romantic involvement, proportion of pledgers) of the determinants of pledging to calculate the predicted log odds of pledging for our debut models. Since all the variables predicting intercourse are also in the pledge prediction equation, by definition one throws away the unique contribution pledging makes because the predicted score would consist only of the contribution the other covariates make to pledging. Since we control for all of these in the sexual debut model, the predicted odds of pledging should not have an effect by definition. Unobserved heterogeneity of pledgers, in a way, is exactly what makes them pledgers and different from others. Of course, in the debut models, this is not technically unobserved since we measure it as pledge. But it is unobserved in the pledge model-it is exactly the part we would throw away if we used the predicted odds. This would not be the case if we had measures of the predictors of pledging before pledging occurs. But our data do not allow us to do this. 
TABLE 9

Transition to First Intercourse: Nonblack Respondents, Model with PeriodSPECIFIC EFFECTS

\begin{tabular}{|c|c|c|c|c|}
\hline & \multicolumn{3}{|c|}{ RELATive Risks } & \multirow{2}{*}{$\begin{array}{c}\text { EFFect Size } \\
\text { Tendency }\end{array}$} \\
\hline & Early & Middle & Late & \\
\hline Female & 1.07 & $3.83^{*}$ & $15.96^{* *}$ & Increasing with age \\
\hline Hispanic & .99 & 1.30 & $2.02^{* * *}$ & Increasing with age \\
\hline Hispanic female & 1.19 & $.54^{* * *}$ & $.33^{* *}$ & Increasing with age \\
\hline Asian ........... & .85 & $.30^{* * *}$ & 1.06 & Middle \\
\hline Single-parent family & 1.37 & 1.08 & 1.34 & NS \\
\hline Step- or foster family . & 1.18 & $1.29^{*}$ & 1.06 & Stronger early \\
\hline SES & .93 & .99 & 1.05 & NS \\
\hline $\mathrm{SES} \times$ female $\ldots \ldots \ldots \ldots \ldots \ldots \ldots$ & .97 & .95 & $.88^{* * *}$ & Late \\
\hline Closeness to parents $\ldots \ldots \ldots \ldots \ldots \ldots$ & $.67^{* * *}$ & 1.05 & .87 & Early \\
\hline Perceived parental disapproval ....... & $.78^{* *}$ & $.84^{* *}$ & $.81^{* *}$ & Always \\
\hline In romantic relationship $\ldots \ldots \ldots$ & $2.09^{* *}$ & $3.18^{* * *}$ & $4.17^{* *}$ & Increasing \\
\hline$N$ romantic partners $\ldots \ldots \ldots$ & $1.31^{* *}$ & $1.18^{* *}$ & 1.09 & Decreasing \\
\hline Emotional commitment $\ldots \ldots \ldots \ldots \ldots$ & 1.08 & $1.20^{* *}$ & 1.11 & Middle \\
\hline Embeddedness in peer group & 1.01 & $.85^{*}$ & 1.02 & Middle \\
\hline School attachment & $.80^{*}$ & $.80^{* * *}$ & .87 & Early and middle \\
\hline Unpopular in school network ......... & .91 & .88 & .77 & Increasing \\
\hline Pubertal development $\ldots \ldots \ldots$.... & $1.41^{* *}$ & 1.12 & 1.10 & Decreasing, early \\
\hline Add Health verbal test score & 1.00 & .99 & 1.00 & NS \\
\hline GPA $\ldots \ldots \ldots \ldots \ldots \ldots \ldots \ldots \ldots \ldots \ldots \ldots$ & $.75^{* *}$ & .91 & .98 & Decreasing, early \\
\hline School sports participation & 1.00 & 1.07 & .91 & NS \\
\hline Sports $\times$ female $\ldots \ldots \ldots \ldots$ & .80 & $.81^{*}$ & 1.05 & Middle \\
\hline Self-esteem $\ldots \ldots \ldots \ldots \ldots \ldots \ldots \ldots \ldots$ & 1.17 & 1.05 & $1.66^{* *}$ & Late \\
\hline Self-esteem $\times$ female $\ldots \ldots \ldots \ldots \ldots$ & 1.28 & .84 & $.55^{* *}$ & Late \\
\hline Religiosity $\ldots \ldots \ldots \ldots \ldots \ldots \ldots \ldots \ldots$ & 1.00 & $.80^{* * *}$ & $.80^{* *}$ & Middle and late \\
\hline Pledge $\ldots \ldots \ldots \ldots \ldots \ldots \ldots \ldots \ldots \ldots \ldots$ & 3.73 & $.65^{*}$ & 1.09 & Middle \\
\hline Socially closed school $\ldots \ldots \ldots \ldots \ldots$ & 1.33 & 1.08 & .94 & NS \\
\hline Pledge in socially closed school ....... & $.12^{* *}$ & .50 & .37 & Early \\
\hline$\%$ pledgers (same sex) & .99 & 1.01 & 1.00 & NS \\
\hline$\%$ pledgers $\times$ closed school $\ldots \ldots \ldots$ & .99 & 1.00 & 1.02 & NS \\
\hline Pledge $\times \%$ pledgers $\ldots \ldots \ldots \ldots \ldots$ & $.92^{*}$ & .98 & .98 & Decreasing \\
\hline Pledge $\times \%$ pledgers closed school $\ldots$ & $1.12^{*}$ & 1.05 & 1.04 & Decreasing \\
\hline
\end{tabular}

Note. - Stages of adolescence are early, 12.5 years up to 15.5 years; middle, 15.5 years up to 17.5 years; late, 17.5 years and older. $N$ of events $=166$ for early, 321 for middle, and 203 for late; $N$ of cases $=5,679 . \chi^{2}(d f)$ is 490 (96). Coefficients for baseline rate are omitted from the table. NS $=$ not significant. ${ }^{\text {a }}$ For white females, this is a "catch up" effect.

* $P \leq .05$, one-tailed test.

** $P \leq .05$, two-tailed test. 
If there are too many pledgers, the pledge effect disappears. Pledging will work only insofar as it is nonnormative and constitutive of individual identity in the larger adolescent subculture. The upper bound on pledging's effectiveness provides a cautionary note to those interested in universal social policies. We discuss this further below.

\section{RELAXING THE PROPORTIONAL HAZARD ASSUMPTION}

The models presented so far assume the effects of explanatory variables to be constant over time. There are reasons to assume, however, that some factors are more important early on in the process while others figure more prominently later on.

We are especially interested in the effectiveness of the pledge across the course of adolescence. In the following analyses, reported in table 9 and 10, we therefore relax the proportionality assumption and estimate a model in which the effect of all the independent variables is allowed to vary across time periods. This involves estimating a great number of parameters. To ensure that there are enough events and variation in the independent variables for each time period, we divide the observed age axis into three time periods, which roughly correspond to early (12.5 years to 15.5 years), middle (15.5 years to 17.5 years), and late adolescence (17.5 and older). For black adolescents, we choose slightly different age periods that reflect the earlier onset of puberty and sexual behavior. The results are reported in table 9 for nonblacks and table 10 for blacks. The results for blacks are based on a rather small number of events and should be interpreted with care.

The direct gender effect increases with age as girls catch up with boys. Hispanic adolescents differ from whites mainly in middle and later adolescence, Asians in middle adolescence (table 9). Our expectation was that parents' influence on the behavior of teens would be greatest in early adolescence and decline later as their children achieve more independence and autonomy. For nonblack adolescents, this hypothesis is borne out. Closeness to parents has a significant effect only in early adolescence. Recall that it was not significant in the simpler model reported in table 7. With respect to family type, the results are less conclusive although there is a tendency for the effect size to be stronger in early and middle adolescence. For girls only, parents' SES has significant effects only in late adolescence. Perceived parental disapproval of sex, however, is a strongly delaying factor throughout adolescence (table 9). The timevariant influence of family type is more pronounced for black adolescents (table 10). The coefficients for closeness to parents and parental disap- 
American Journal of Sociology

TABLE 10

Black Respondents, Model with Period-Specific Effects

\begin{tabular}{|c|c|c|c|c|}
\hline & \multicolumn{3}{|c|}{ ReLative Risks } & \multirow{2}{*}{$\begin{array}{c}\text { EFFECt Size } \\
\text { Tendency }\end{array}$} \\
\hline & Early & Middle & Late & \\
\hline Female & 7.80 & 1.83 & 2.20 & (Decreasing with age) \\
\hline Single-parent family & $2.17^{*}$ & 1.07 & 1.01 & Early \\
\hline Step- or foster family $\ldots \ldots \ldots \ldots \ldots$ & $3.36^{* *}$ & .84 & .89 & Early \\
\hline SES & 1.06 & .96 & .99 & NS \\
\hline Closeness to parents & .85 & 1.00 & .89 & NS \\
\hline Perceived parental disapproval $\ldots \ldots$. & .83 & .99 & 1.02 & (Decreasing) \\
\hline In romantic relationship $\ldots \ldots \ldots \ldots \ldots$ & $4.98^{* *}$ & $3.26^{* *}$ & $6.18^{* *}$ & Increasing \\
\hline$N$ romantic partners ................... & 1.16 & 1.13 & .76 & NS \\
\hline Emotional commitment $\ldots \ldots \ldots \ldots \ldots$ & .94 & .90 & .72 & (Increasing) \\
\hline Emotional commitment $\times$ female $\ldots$ & 1.28 & 1.05 & 1.20 & NS \\
\hline Embeddedness in peer group ......... & .72 & .98 & 1.24 & NS \\
\hline School attachment $\ldots \ldots \ldots \ldots \ldots \ldots \ldots$ & 1.07 & 1.37 & $.66^{*}$ & Late \\
\hline Unpopular in school network & .62 & .70 & 1.40 & NS \\
\hline Pubertal development $\ldots \ldots \ldots$. & $1.83^{*}$ & .99 & 1.49 & Early \\
\hline Pubertal development $\times$ female $\ldots .$. & $.44^{*}$ & .90 & .75 & Early \\
\hline Add Health verbal test score ......... & 1.01 & 1.00 & $.97^{* *}$ & Late \\
\hline GPA $\ldots \ldots \ldots \ldots \ldots \ldots \ldots \ldots \ldots \ldots \ldots \ldots \ldots \ldots \ldots \ldots \ldots$ & .90 & .74 & .85 & (Middle) \\
\hline School sports participation $\ldots \ldots \ldots \ldots$ & 1.32 & 1.35 & $1.82^{*}$ & Increasing \\
\hline Sports $\times$ female $\ldots \ldots \ldots \ldots \ldots \ldots \ldots$ & .61 & .70 & .66 & NS \\
\hline Self-esteem $\ldots \ldots \ldots \ldots \ldots \ldots \ldots \ldots \ldots \ldots \ldots \ldots \ldots$ & .71 & .91 & 1.32 & NS \\
\hline Religiosity $\ldots \ldots \ldots \ldots \ldots \ldots \ldots \ldots \ldots \ldots \ldots \ldots \ldots \ldots \ldots$ & 1.06 & .84 & .90 & (Middle) \\
\hline Pledge $\ldots \ldots \ldots \ldots+\ldots$ & 1.29 & .69 & .97 & (Middle ) \\
\hline
\end{tabular}

Note.-Stages of adolescence differ from nonblack respondents and are early, 12.5 years up to 15 years; middle, 15 years up to 17 years; late, 17 years and older. $N$ events is 38 for early, 66 for middle, and 48 for late; $N$ cases is $997 . \chi^{2}(d f)$ is $68(69)$. Coefficients for baseline rate are omitted from the table. $\mathrm{NS}=$ not significant

* $P \leq .05$, one-tailed test.

** $P \leq .05$, two-tailed test.

proval have the expected direction, are greater in early adolescence, but are not significant.

For black adolescents and for others, the effect of being in a romantic relationship is almost twice as large in middle and late adolescence than in early adolescence. The effect of number of prior romantic partners decreases. First sex happens in the context of a romantic relationship. Adolescents who date a lot at an early age will also have sex earlier than others. For nonblack adolescents, emotional commitment within relationships and embeddedness of the relationship in the adolescents' social world have the most pronounced effects in middle adolescence.

School attachment is a protective factor in early and middle adolescence for nonblack adolescents. For blacks, in contrast, it is only significant and negative in late adolescence (table 10). The effect of social isolation is, compared to that in the model in tables 7 and 8 , reduced in size (except 
for late adolescence), and not significant. As expected, pubertal development is most important for young adolescents; each one-unit change in the five-point scale is estimated to increase the transition rate by $41 \%$, other things equal, while for young black males, it is almost twice as large $(83 \%)$. As in the simpler proportional hazard model reported in tables 7 and 8, cognitive ability is not related to the timing of first intercourse for nonblacks (but it does delay intercourse for older blacks). Both academic achievement and sports participation (for nonblack girls only) have the strongest delay effect in early and middle adolescence. The gendered pattern of self-esteem's influence for nonblacks is pronounced only in late adolescence, when girls with high self-esteem are actually less likely to experience sexual debut than are girls with low self-esteem. This negative effect of self-esteem for girls is consistent with the idea that girls with a developed sense of self find it easier to refuse sex when negotiating romantic behavior with their male partners (Martin 1996). The change of the effect over time and the gender interaction account for the fact that many studies do not find any effect of self-esteem on sexual initiation (Hofferth 1987; Brown and Theobald 1999). Religious adolescents are slower to experience first intercourse only in middle and late adolescence

\section{PLEDGING CONTEXT AND AGE DEPENDENCY}

The context interaction effect between pledging, \%pledgers, and school type is extremely strong only in early adolescence (table 9). ${ }^{42}$ In middle adolescence, the effect of pledging is "individualized," while in late adolescence neither pledging nor the interaction effects are significant. When omitting the interaction terms, we obtain an estimated relative risk for pledgers of $.79(P=0.28)$ in the early period, $.49(P=0.0002)$ in the middle period, and $.72(P=.11)$ in the late period: only the coefficient for middle adolescence is significantly different from zero. This timing pattern is similar in the model for blacks, although none of the coefficients are significant. This age dependency further conditions the effectiveness of the pledge. It works, but only for a subset of adolescents in specific social contexts defined by the proportion of other pledgers.

Overall, relaxing the assumption of time-constant effects yields different conclusions about the factors influencing sexual initiation. Focusing on age dependencies provides additional information about the effectiveness of various factors across age periods. The idea that individual attitudes and personality become more important as adolescents get older is borne

\footnotetext{
${ }^{42}$ Because of convergence problems, we could not test the time dependence of the context effect for black adolescents (table 10).
} 
out by this model. It is noteworthy that parental disapproval of sex is strong throughout adolescence. ${ }^{43}$ For older adolescents, first sex is more likely to happen in the context of a romantic relationship. For nonblacks, the effect of pledging is highly context dependent in early adolescence, more individualized in middle adolescence, and probably absent or much smaller in late adolescence. Thus, while it may be unlikely that most pledgers will delay intercourse until marriage, pledging significantly delays intercourse for the majority of pledgers in early and middle adolescence.

\section{PROMISE KEEPERS AND PROMISE BREAKERS}

Critics of the pledge movement suggest that pledgers who break their promise and experience sexual intercourse will suffer negative psychological consequences. To assess this criticism, we consider two scales that measure psychological well-being, the self-esteem scale used in the transition models above, and an 11-item depression scale. For all groups except black males, teens who had first intercourse experience a loss of selfesteem compared to those who remained virgins (results not shown; tables available from the authors). Female pledgers experience an increase in self-esteem between waves, and the interaction effect between pledging and having intercourse is not significant for any group. We found no indication that changes in self-esteem associated with intercourse depend on the timing of intercourse or on age at the time of the first wave interview. Hence, pledgers do not lose more self-esteem when they break their promises than is experienced by nonpledgers who have first intercourse. The same obtains when using the depression scale, and in a multivariate model controlling for relationship with parents, religiosity, school integration, academic orientation, network position, and romantic involvement. Thus, pledging has no negative consequences in terms of psychological well-being, even for teenagers who break their promise.

We do find, however, an effect of pledging on the likelihood of using contraception at first intercourse. In this analysis, reported in table 11, we look only at teens who had first intercourse between waves. We use a set of predictors similar to that used in our model of first intercourse. ${ }^{44}$

\footnotetext{
${ }^{43}$ Parents' own report of disapproval of their teens' having sex is only weakly related to adolescents' sexual behavior (results not shown). Most adolescents do not really know what their parents think. But what they believe their parents think is what counts.

${ }^{44}$ Information on romantic relationship is averaged over the observation period (until first intercourse occurs). Alternative specifications (last or current relationship) yield the same conclusions.
} 
Virginity Pledges

TABLE 11

Logistic Regression of Contraceptive Use at First

INTERCOURSE FOR NONBLACKS

\begin{tabular}{|c|c|c|}
\hline & $\begin{array}{l}\text { Odds } \\
\text { Ratio }\end{array}$ & $95 \% \mathrm{CI}$ \\
\hline Age & 1.05 & $.91-1.21$ \\
\hline Age at first intercourse ${ }^{a}$ & 1.00 & $.99-1.01$ \\
\hline Female $\ldots \ldots \ldots \ldots \ldots \ldots \ldots \ldots$ & 1.10 & $.77-1.58$ \\
\hline Hispanic $\ldots \ldots \ldots \ldots \ldots \ldots \ldots \ldots$ & $.68^{*}$ & $.46-1.00$ \\
\hline Asian $\ldots . . . . . . . . . . . .$. & $.34^{* *}$ & $.14-.84$ \\
\hline Single-parent family $\ldots \ldots \ldots \ldots \ldots$ & .76 & $.49-1.17$ \\
\hline Step- or foster family $\ldots \ldots \ldots \ldots$ & $.68^{* * *}$ & $.50-.91$ \\
\hline SES $\ldots \ldots \ldots \ldots \ldots \ldots \ldots \ldots \ldots \ldots$ & .95 & $.89-1.02$ \\
\hline Parental closeness $\ldots \ldots \ldots \ldots \ldots$ & 1.01 & $.75-1.34$ \\
\hline Parental disapproval .... & 1.04 & $.84-1.28$ \\
\hline School attachment $\ldots \ldots \ldots \ldots \ldots \ldots$ & 1.09 & $.87-1.38$ \\
\hline Unpopular in school network $^{\mathrm{b}} \ldots$ & .88 & $.59-1.32$ \\
\hline Add Health verbal test score ...... & 1.01 & $.99-1.02$ \\
\hline GPA $\ldots \ldots \ldots \ldots \ldots \ldots \ldots \ldots \ldots$ & $1.34^{* *}$ & $1.10-1.64$ \\
\hline Self-esteem ........ & 1.05 & $.77-1.42$ \\
\hline Religiosity ........ & .96 & $.81-1.14$ \\
\hline Pledge...... & $.65^{* *}$ & $.43-.99$ \\
\hline
\end{tabular}

NOTE. - All variables were measured at wave 1 , in-home interview except where noted. $N=1,329 . \chi^{2}(d f)$ is $56.11(17)$ and is significant at the .01 level. SEs are adjusted for clustering, weighted data.

${ }^{a}$ Measured at wave 2, in-home interview.

${ }^{\mathrm{b}}$ Measured at time of in-school interview.

$* P \leq .05$, two-tailed test.

$* * P \leq .01$.

Table 11 shows the results of a logistic regression of the probability of using contraception as a function of SES, relationship to parents, school integration, academic achievement, religiosity, and pledge status. ${ }^{45}$ Neither parents' SES, nor age at first intercourse, nor cognitive ability are significant in this model. On the other hand, GPA, which is conceptually closer to academic aspirations, has a strong effect on contraceptive use. This suggests that contraceptive use is strongly associated with investments adolescents make in school. Hispanics and Asians are less likely to use contraception than are whites. We found no indication for gender/ ethnicity interaction effects. The key finding for this article is the effect of pledge status. The estimated odds for contraceptive use for pledgers

${ }^{45}$ We have omitted black respondents from this model because we know the sample to be selective. In this sample, blacks are more likely than any other group to use contraception at first intercourse-about $75 \%$ of all black teens do, and the multivariate model used for blacks yields little information about blacks' contraceptive behavior. With the exception of GPA, none of the predictors accounts for differences between users of contraception and others for blacks. 
are about one-third lower than for others. Pledgers are less likely to be prepared for an experience that they have promised to forgo. It is hard not to imagine the dissonance that would arise if they were contraceptively prepared. This suggests that pledgers, like other adolescents, may benefit from knowledge about contraception and pregnancy risk, even if it appears at the time that they do not need such knowledge.

\section{DISCUSSION}

Many adults are concerned about adolescent sex, and many adolescents are concerned as well. Many adults worry about the negative consequences arising from early transitions to sexual behavior. They seek ways to help adolescents negotiate the complex and contradictory messages they get about sex. The pledge movement is organized by adults for adolescents. It is designed to help adolescents say no thank you to sex. In general, if adolescents do say no thank you, they are better off. They have fewer health risks, and they feel better about themselves. Programs that work to delay first intercourse make a contribution to adolescent health. Even if we did otherwise, and even if some adolescents feel that they ought to do otherwise, they are better off waiting. This is especially true for girls, who are better able to negotiate better (safer) sex the older they are.

Pledgers come from normative backgrounds. They pledge because they do not want to have sex. They do not need to pledge to avoid sex, but pledging helps them not have sex. On the average, it reduces the baseline rate of time to sexual debut by $34 \%$. A pledger with four romantic partners has the same relative risk of sexual debut as a comparable nonpledger with no romantic partners. The pledge effect is not a selection effect. It is real and it is substantial. But it is not a panacea for all of our adolescents. It works best for younger adolescents. It works only in specific contexts. The limits of the pledge's effectiveness provide insight into the mechanisms by which it operates.

The key mechanism is that pledging creates a moral community. Pledgers participate in this community and take on a pledge identity. Their joint participation sustains this identity and makes it meaningful for their behavior. Movement organizers are well aware that their movement will be successful if it builds a new identity. Pledge paraphernalia available on the Internet provides visible markers of identity, pledge rings, pledge music, pledge books. Pledgers need to be visible to others. This is because pledging outside a community of pledgers provides no protection for adolescents. Pledgers may pledge, but they cannot determine the effect of the pledge all by themselves.

The importance of pledging for the pledge movement itself is significant. 


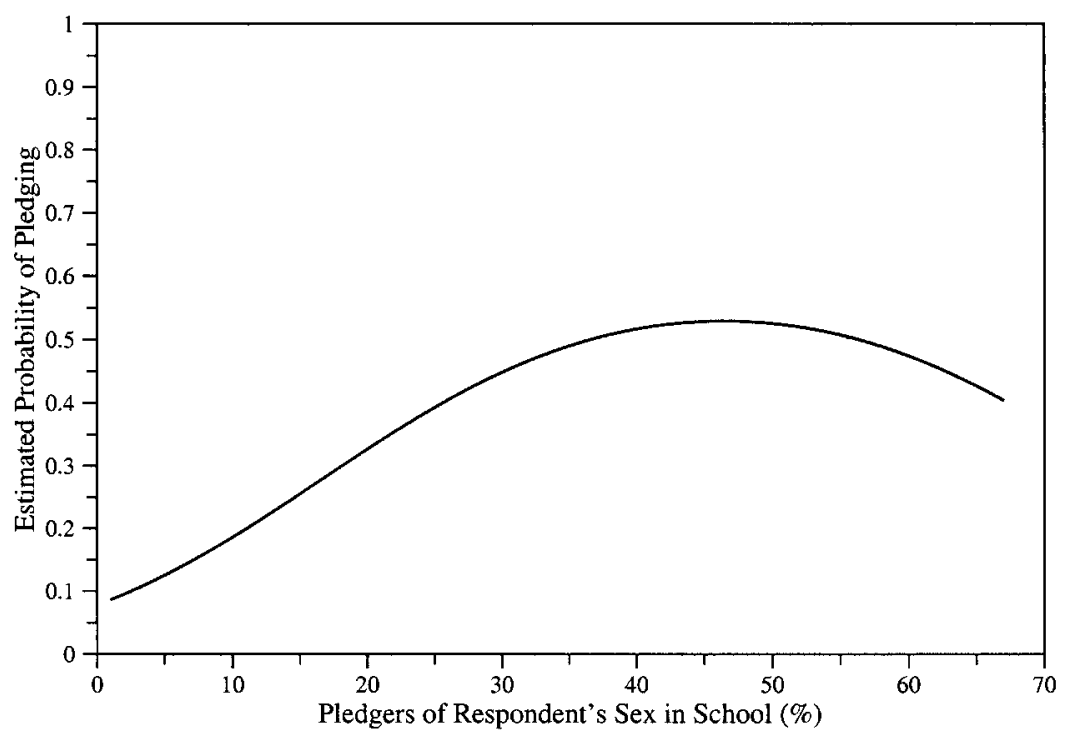

FIG. 4.-Estimated probability of pledging and school context

As reported in appendix B, the effect of other pledgers among same sex adolescents in each school on pledging is curvilinear. Up to a threshold of around $40 \%$ pledgers, all other covariates of pledging considered at their means and modes, the probability of pledging increases by $1 \%$ for every additional $1 \%$ same-sex pledger in an adolescent's school. At higher levels of pledgers, the curve flattens out and the effect turns negative. This relationship is illustrated in figure 4 .

Pledging thus provides fuel for its own growth and success, up to a limit. This phenomenon of self-sustained growth, with an associated threshold, is common to identity movements. For an identity to be meaningful-that is, to have a meaningful relationship to behavior-it must be embedded in and sustained by an interacting population of persons. Public pledge events work to encode pledging into a moral community. The community is effective only if it has self-conscious recognition, which presumes minority status.

The contextual effects we identify point to the mechanisms through which the pledge effect operates. When the pledge works, it works because pledgers are embedded in an identity movement. Like other movement identities, the pledge identity is relatively fragile and meaningful only in contexts where it is at least partially nonnormative. If most adolescents were to pledge, there would be no pledge effect on the transition to intercourse. 
Not surprisingly, as with most social movements, the pledge movement has contradictory elements. Pledge rhetoric stresses making your own decision and getting away from the crowd. But the movement produces as a by-product of its core activity (public pledging) something even better than a crowd-specifically, a visible moral community. Because pledging generates a public moral community, pledging also provides, consequently, both a cognitive foundation for new identity (someone who has made a commitment) and the structural context (a community of interacting pledgers) in which identity can be articulated and practiced. The moral community of pledging is the key to its success and failure.

Critics of the pledge movement are as concerned about adolescent sex as are the supporters of the movement. These critics are both wrong and right about the pledge. They are wrong when they think it does not work. But they are right when they think that it cannot work as a universal strategy. Of course, pledging will not work for adolescents who want to have sex. That is always true. But pledging does not work in some social contexts even for pledgers who do not want to have sex. If pledgers attend a school that is the focal point of their social relationships, and if too many other students in their school pledge, the pledge effect disappears. In these contexts, about one-third of schools in the Add Health sample, pledgers transition to first sex at the same rate as nonpledgers. Beyond this, if pledgers do have sex, they are less likely to be contraceptively prepared than nonpledgers.

\section{IMPLICATIONS FOR SOCIAL POLICY}

Individuals decide to pledge or not to pledge. The pledge movement attracts adults and adolescents who are pledge supporters. Pledgers do not want to have sex when they pledge, but they cannot determine the effect of the pledge all by themselves. In some contexts, if there are no other pledgers around, the pledge effect disappears. In other contexts, if there are too many pledgers around, the pledge effect disappears. The contextual effect we identify suggests interesting limits to the applicability of a universal, pledge-based policy. Like most other things, pledging works in moderation. Universal pledge-based policies will succeed only if they fail. Pledging is rooted in its nature as a minority identity movement. Movement leaders are aware of this as well. They recognize that pledging is not for everyone. They understand the nonlinear effect of other pledgers on the probability of pledging. Policy makers should recognize that the pledge works because not everyone is pledging. 
Virginity Pledges

\section{APPENDIX A}

\section{Sample Selectivity}

As part of the ACASI section of the in-home interviews, adolescents were asked whether they had ever had sexual intercourse. Those who reported intercourse were asked when they had intercourse for the very first time (year and month). Figure A1 shows the survivor function for the transition to first intercourse, combining data from both waves,${ }^{46}$ for the full sample, by gender and race (all adolescents with valid data on month and year). In contrast to earlier research, among nonblacks we find gender differences only at early ages. Later, girls "catch up" and the two functions converge ${ }^{47}$ For blacks, gender differences are pronounced until late adolescence, when the survivor functions for girls and boys converge. The median transition age for nonblack teenagers is slightly below 18 years, for blacks, slightly over 16 . These figures are comparable to other national estimates (AGI 1994; Moore, Driscoll, and Lindberg 1998).

The great advantage of longitudinal data resides in the possibility to order presumed causes and effects in time. Since most of our explanatory factors, including whether adolescents had taken a pledge, are measured in the first in-home interview, causal inferences for adolescents who by that time already had experienced first sexual intercourse are limited. Excluding these adolescents from the sample means that our sample is selective for later transitions to first intercourse. We now explore the impact of this selectivity. In our analyses, we consider only adolescents who were virgins at their first in-home interview. ${ }^{48}$ Forty-four percent of

\footnotetext{
${ }^{46}$ Adolescents participating in both waves were asked twice about the date they had intercourse for the first time. In some of these cases, there is a inconsistency between the data collected in the two waves. The solution we adopted was to chose the date given in the first wave on the grounds that recollection of the timing of salient events in the life course declines in accuracy over time-the longer the time between the survey and the event in question, the more likely are recall errors (Brückner 1995). Since in the case of sexual debut underreporting is more likely than overreporting, we adopted this strategy also for teens who reported sexual debut in the first wave but claimed to be virgins in the second wave. A comparison of the survivor functions resulting from choosing either wave 1 or wave 2 data shows that the differences are minimal and have no impact whatsoever on the estimates of median transition age or the proportion of virgins at any other age.

${ }^{47}$ In contrast to other studies, Add Health data do not show gender differences in the timing of first intercourse for white adolescents. This is likely the result of ACASI technology. Because interviewers were not privy to adolescent responses, girls may have felt freer to report earlier transitions. Boys may have felt freer to admit to a later transition. Turner et al. (1998) report similar changes for abortion arising from ACASI interviews.

${ }^{48}$ We also exclude a few adolescents who report to have had intercourse before age 10 (age 9 for black males).
} 


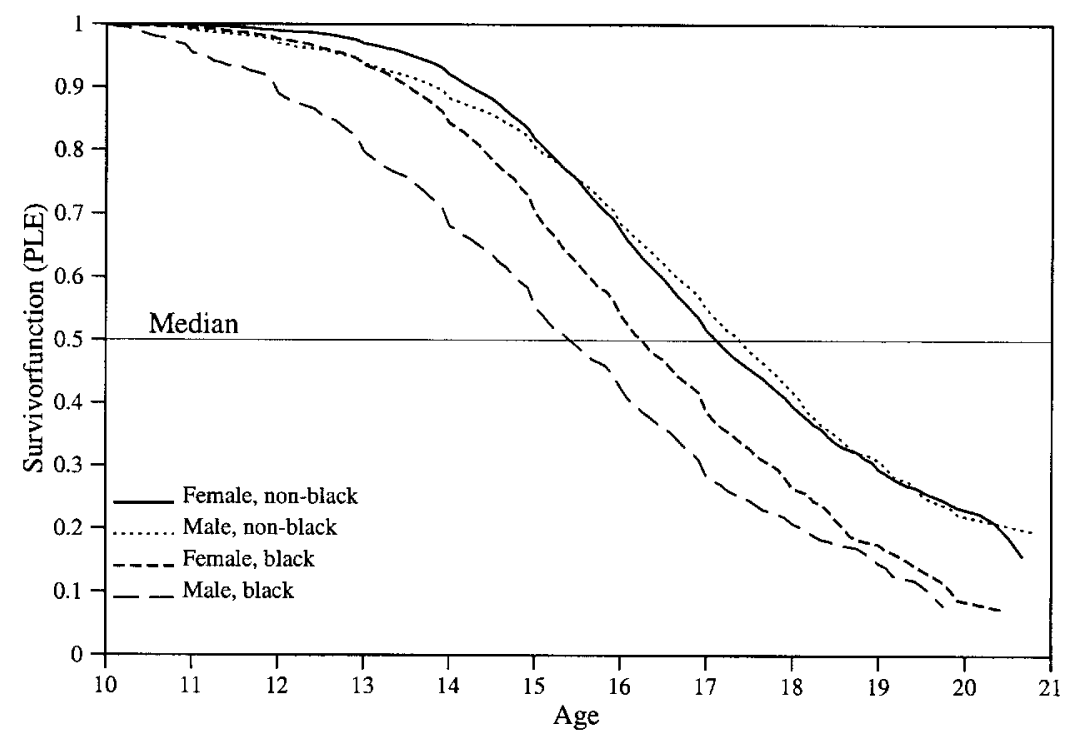

FIG. A1.-Transition to sexual intercourse by race and gender, full sample

teens in the in-home sample had already experienced sexual debut by the time they were interviewed. Although the internal validity of causal inferences is strengthened by concentrating the analysis on adolescents who were still at risk for initiating sexual activity when data on explanatory variables were collected, we have to be concerned with the external validity of the resulting restricted sample. Specifically, the effects of factors influencing the age of sexual initiation can be underestimated in a sample from which part of the population at risk has already dropped out. Figure A2 shows a comparison between the full Add Health sample and the restricted sample that we described above.

For nonblack respondents, who on average are older at sexual initiation, the survivor functions for the full and restricted samples are identical until age 15, after which they diverge somewhat. At the end of the observation period, the estimated proportion with intercourse is very similar. For black adolescents, the restricted sample is far more selective toward late transitions. The estimated median transition age from the restricted sample is almost one year higher than that estimated from the full sample for black adolescents.

In the intercourse models, adolescent pledge status is the key independent variable we focus on. Adolescents who were not married at the time of the first in-home interview were asked whether they had "ever taken a public or written pledge to remain a virgin until marriage." For nonblack 


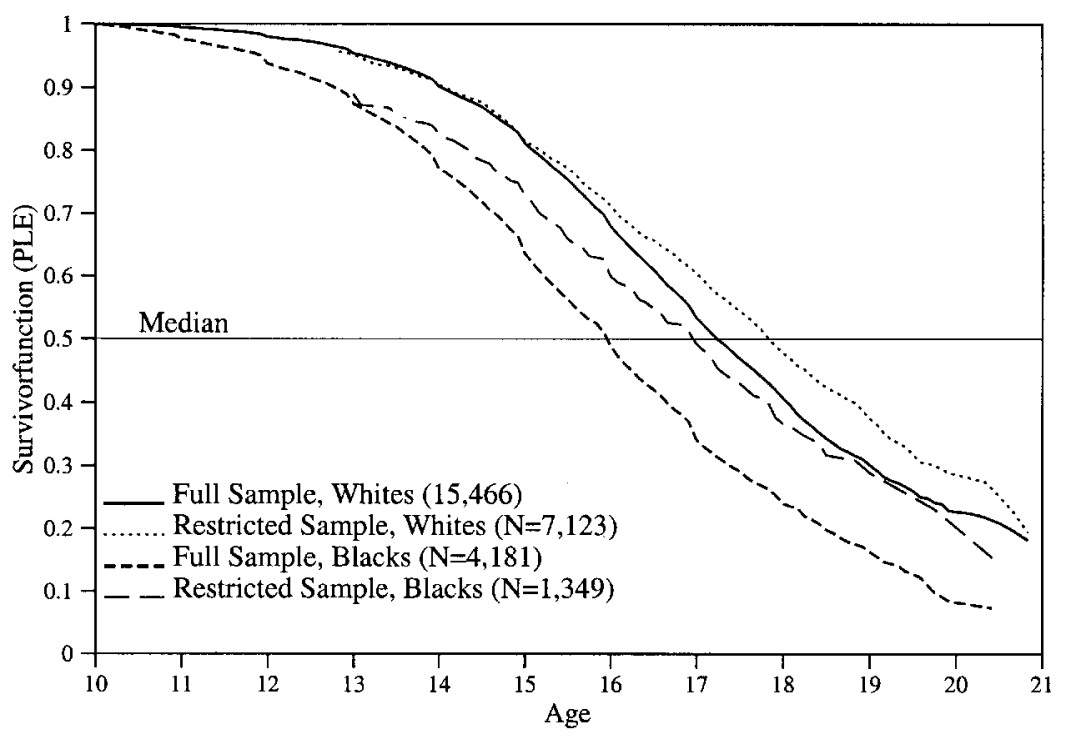

FIG. A2.- Transition to sexual intercourse by race, comparison of samples

females, pledgers transitioned to first intercourse on average more than three years later than nonpledgers (38 months). Because less than half of nonblack male pledgers had experienced sexual initiation, we compare the transition for pledgers and nonpledgers in the lowest quartile. Here, pledgers transitioned to first intercourse on average 2.5 years later than their nonpledging counterparts. For both black females and males, the difference in median transition age between pledgers and others is slightly above two years ( 27 months). For all groups, we observe a substantial delay in sexual debut for pledgers.

For the restricted sample, selected on late intercourse, the difference in median age for nonblack girls is still at 1.25 years. For nonblack males, pledgers transition to first sex 20 months later than nonpledgers. For both male and female blacks, there is no difference in median transition age between pledgers and others. Compared to the full sample, pledgers are overrepresented in this sample, especially among black girls. Pledgers make up $30 \%$ of the black female restricted sample compared to $19 \%$ of the full sample (for black boys, the respective numbers are $9 \%$ vs. $17 \%$, for nonblack boys $9 \%$ vs. $17 \%$, and nonblack females $16 \%$ vs. $23 \%$ ). Thus, with our restricted sample for black adolescents we cannot show a pledge effect - however, pledging is associated with being in our sample (since pledgers have intercourse later, their chances to be part of our sample are greater). 
Sample selectivity also results from missing data. Like all surveys, Add Health data suffers from missing data. Throughout, we have replaced missing values with the means for the associated race/sex group. In all cases we control for measurement error that may be introduced by mean imputation. None of the dummy variables were significant in the models reported below. ${ }^{49}$ Unfortunately, mean substitution was not always possible. A key requirement for our models involved timing relationships with respect to intercourse. We therefore excluded all respondents who had missing data either on the occurrence or date of first intercourse or on starling and ending times of romantic relationships. In addition, we lost a few respondents who had either missing data on the pledge question, or were not linked to any of the schools in the sample. Of the 8,150 respondents who were still under risk to experience first intercourse at the time of the first in-school interview and participated in the second, we were able to retain 6,776 cases in the event history models reported below. Most of these losses are due to missing start and end dates in the relationship data. We found no indication that respondents with missing dates were different from others in terms of their transition behavior or in terms of the distribution of independent variables used in this analysis. The results of these analyses are available from the authors.

Problems of selectivity are certainly present for black adolescents in our sample. For blacks, selectivity on the dependent variable all but wipes out the effect of our key independent variable, pledging. Given these problems, we cannot draw inferences about race differences from our sample. Rather, we focus on gender differences among black teenagers, asking the reader to keep in mind that the results presented below for black adolescents should not be taken to be representative for the population. For white adolescents, a delay of sexual debut associated with pledging observed in the full sample is somewhat reduced but still substantial..$^{50}$ In sum, we are more likely to under- rather than overestimate a delaying effect of pledging on sexual debut.

\footnotetext{
${ }^{49}$ Missing data problems are especially great for popularity. For the popularity measure, we need full information on the entire friendship network in the school. In the 24 schools where the response rate was too low, this measure was set to missing. We tested models both by including only cases with valid data on these variables and by excluding these two variables and found that the results are stable across all specifications.

${ }^{50}$ We explored the extent of sample selectivity by running a multivariate hazard model for both samples and comparing the estimated effects across samples, including only explanatory variables that do not change over time and are not affected by sexual initiation. With the exception of the early gender difference (see fig. A1) that we cannot show with the restricted sample, the models for nonblack teenagers look very similar in terms of effect sizes and direction (results not shown, tables available on request). Again, for black teenagers, the restricted sample is clearly selective.
} 
Virginity Pledges

\section{APPENDIX B}

Who Pledges?

In this section, we present a multivariate model of pledging with the goal of further exploring what differentiates pledgers from others. Because the differences we observe might be due to selection, we model the probability of pledging between the two waves of in-home interviews. This necessitates the use of a different sample than the sample we use in our transition models. First, we need to exclude all adolescents who said they had taken a pledge in the first wave. Adolescents who had already experienced sexual initiation at Wave 1 are excluded from the present analysis as well since adolescents who have had sex are very unlikely to pledge. This yields a sample of 6,849 persons, of which $699(9.41 \%)$ report that they have taken a pledge between waves. ${ }^{51}$ Compared to the wave 1 pledgers included in subsequent analyses of sexual debut, the pledgers in this sample have joined the pledge movement later in its history.

We estimate a logistic regression model with the same covariates we use in the transition rate models, including age as an additional covariate. ${ }^{52}$ Relationship information cannot be treated as time-varying covariate in this type of model. We therefore include the relationship status as measured at the time of the first in-home interview, the number of partners an adolescent had up to that date, and the mean characteristics of those relationships. The results are reported in table $\mathrm{B} 1 .^{53}$

While pledgers are more likely to be female once we control for other factors, the gender effect disappears. All variables associated with parents and family background have virtually no effect on pledging. Although we find a bivariate difference with respect to parental disapproval of sexual initiation and parental closeness, these differences disappear in the multivariate model, when controlling for religiosity and school context. School integration, as well as academic achievement and sports participation are also not associated with a greater propensity to pledge. Pubertal development and cognitive ability, however, both decrease the likelihood

${ }^{51}$ We lose fewer cases due to missing data here because we do not need to know the exact dates of relationship start and end. Adolescents were asked whether a relationship was still on going and that information was used to extract the relationship status at the time of the first in-home interview. Cases where the relationship status was unclear were included, together with a variable flagging them.

${ }^{52}$ Questions on attitudes about sex where only asked of respondents that were either older than 14 or reported that they had experienced sexual debut. For this reason, we could not use these data in the models presented in this article.

${ }^{53}$ Because pledging may effect some of the variables described in table 2, e.g., selfesteem and one's relationship to parents, and because we look at a different sample, the means of independent variables for both groups are reported in cols. 1 and 2 of table B1. 
American Journal of Sociology

TABLE B1

Determinants of Pledging

\begin{tabular}{|c|c|c|c|c|}
\hline & \multicolumn{2}{|c|}{ MEAN } & \multirow{2}{*}{$\begin{array}{l}\text { ODDS } \\
\text { RAtio }\end{array}$} & \multirow[b]{2}{*}{$95 \% \mathrm{CI}$} \\
\hline & Pledgers & Nonpledgers & & \\
\hline $\operatorname{Age}^{\mathrm{a}}$ & 15.43 & 15.43 & .96 & $.90-1.02$ \\
\hline Female & $.60^{\mathrm{b}}$ & .49 & .98 & $.77-1.25$ \\
\hline Black $\ldots \ldots \ldots \ldots \ldots \ldots \ldots \ldots \ldots \ldots \ldots \ldots \ldots$ & .18 & .16 & .85 & $.64-1.13$ \\
\hline Hispanic $\ldots \ldots \ldots \ldots \ldots \ldots \ldots \ldots$ & .18 & .16 & .85 & $.60-1.22$ \\
\hline Asian $\ldots \ldots \ldots \ldots \ldots . . . .$. & $.12^{\mathrm{b}}$ & .07 & $1.71^{* *}$ & $1.09-2.69$ \\
\hline Single-parent family ${ }^{\mathrm{a}} \ldots \ldots \ldots \ldots$ & .21 & .21 & 1.09 & $.81-1.49$ \\
\hline Step- or foster family ${ }^{a}$ & .17 & .17 & 1.15 & $.86-1.54$ \\
\hline $\mathrm{SES}^{\mathrm{a}} \ldots \ldots \ldots \ldots \ldots \ldots$ & 5.89 & 6.15 & .97 & $.93-1.01$ \\
\hline Closeness to parents $^{\mathrm{a}}$ & $4.47^{\mathrm{b}}$ & 4.40 & 1.12 & $.89-1.43$ \\
\hline Perceived parental disapproval $^{\mathrm{a}} \ldots$ & $3.67^{\mathrm{b}}$ & 3.52 & 1.08 & $.84-1.39$ \\
\hline In romantic relationship ${ }^{\mathrm{a}} \ldots \ldots \ldots \ldots$ & .19 & .22 & $1.51^{* *}$ & $1.09-2.10$ \\
\hline$N$ romantic partners ${ }^{\mathrm{a}}$ & $.54^{\mathrm{b}}$ & .72 & $.78^{* *}$ & $.64-.96$ \\
\hline Mean emotional commitment ${ }^{a}$ & 1.85 & 2.22 & 1.08 & $.97-1.19$ \\
\hline Mean embeddedness ${ }^{\mathrm{a}}$ & $.83^{\mathrm{b}}$ & 1.05 & .84 & $.67-1.07$ \\
\hline School attachment $^{\mathrm{a}}$.. & 2.87 & 2.78 & 1.09 & $.90-1.33$ \\
\hline Unpopular in school network ${ }^{\mathrm{c}} \ldots$... & .27 & .24 & 1.18 & $.91-1.55$ \\
\hline Pubertal development ${ }^{\mathrm{a}}$ & 2.85 & 2.96 & $.83^{* *}$ & $.70-.99$ \\
\hline Add Health verbal test Score ${ }^{\mathrm{a}} \ldots .$. & $97.12^{\mathrm{b}}$ & 102.30 & $.98^{* *}$ & $.97-.99$ \\
\hline$\ldots \ldots \ldots \ldots \ldots \ldots \ldots \ldots$ & 2.93 & 2.88 & 1.14 & $.97-1.34$ \\
\hline School sports participation ${ }^{c}$ & 1.16 & 1.15 & 1.08 & $.98-1.19$ \\
\hline Self-esteem $^{\mathrm{a}}$. & 3.07 & 3.06 & .89 & $.70-1.14$ \\
\hline Religiosity $^{\mathrm{a}}$ & $2.28^{\mathrm{b}}$ & 1.81 & $1.51^{* *}$ & $1.31-1.74$ \\
\hline$\%$ same-sex pledgers ${ }^{\mathrm{a}}$ & $16.77^{\mathrm{b}}$ & 1.90 & $1.12^{* * *}$ & $1.09-1.15$ \\
\hline$\%$ same-sex pledgers $^{2 \mathrm{a}} \ldots \ldots$ & $404.17^{b}$ & 359.02 & $.99^{* * *}$ & $.98-.99$ \\
\hline
\end{tabular}

Note. $-N$ of cases, measured at wave 2 in-home interview, is 699 for pledgers, 6,150 for nonpledgers. $\chi^{2}(d f)$ is $602(37)$. Coefficients not shown: six denomination categories, eight missing value flags (none significant at $\alpha=.05$ ). SEs adjusted for clustering, weighted data. The coefficient for \% same-sex pledgers ${ }^{2}$ is multiplied by 10 .

Measured at wave 1, in-home interview.

b Significant bivariate differences.

${ }^{c}$ Measured at time of in-school interview.

* $P \leq .05$, one-tailed test.

** $P \leq .05$, two-tailed test.

of pledging substantially. Pubertal development here may indicate increased motivation to engage in sexuality (Udry 1988), which in turn decreases motivation for pledging. Cognitively more able adolescents probably have access to multiple strategies for saying no thank you to sex, and so are less likely to be attracted to the pledge movement. Being in a relationship increases the odds of pledging. This is consistent with a recruitment strategy of the pledge movement that constructs pledging as a token of "true love" between teenagers. There was no interaction effect between being in a relationship and number of prior partners. Thus, adolescents who have experience in the dating game are less likely to 
pledge, regardless of their current relationship status. The nature of the relationship does not play a role for pledging. ${ }^{54}$

The results of this analysis suggest that pledgers tend to be more religious, from more normative backgrounds, and less physically developed than their nonpledging peers. We control for these, and other characteristics, in all of the intercourse models that assess a pledge effect.

\section{APPENDIX C}

\section{Items Used in Index Construction}

Items for self-esteem index.-You have a lot of energy. You seldom get sick. When you do get sick, you get better quickly. You are well coordinated. You have a lot of good qualities. You are physically fit. You have a lot to be proud of. You like yourself just the way you are. You feel like you are doing everything just about right. You feel socially accepted. You feel loved and wanted.

Items for school integration index.-You feel close to people at your school. You feel like you are part of your school. You are happy to be at your school. The teachers at your school treat students fairly. You feel safe in your school.

Closeness to parents.- Most of the time, your mother (father) is warm and loving towards you. You are satisfied with the way your mother (father) and you communicate with each other. Overall, you are satisfied with your relationship with your mother (father).

Religiosity.- How often do you go to church? How often do you pray? How important is religion to you?

Social embeddednes of romantic relatonship.-You went out together in a group. You met your partner's parents. You told other people that you were a couple.

Emotional commitment.-You saw less of other friends so you could spend more time with your partner. You and your partner went out together alone. You gave each other presents. You told each other that you loved each other. You thought of yourselves as a couple.

\section{REFERENCES}

AGI (Alan Guttmacher Institute) . 1994. Sex and America's Teenagers. New York: Alan Guttmacher Institute.

$\rightarrow$ Bearman, Peter S. 1991. "Desertion or Localism? Army Unit Solidarity and Group Norms in the U.S. Civil War." Social Forces 70 (2): 321-42.

Bearman, Peter S., and Hannah Brückner. 1999. Peer Effects on Adolescent Girls'

${ }^{54}$ Restricting the sample only to adolescents that had had at least one relationship by the time of wave 1 does not change these results. 


\section{American Journal of Sociology}

Sexual Debut and Pregnancy. Washington, D.C.: National Campaign to Prevent Teen Pregnancy.

Bearman, Peter S., Jo Jones, and Richard J. Udry. 1997. The National Longitudinal Study of Adolescent Health: Research Design. Carolina Population Center. University of North Carolina at Chapel Hill.

Blau, Peter. 1977. Inequality and Heterogeneity: A Primitive Theory of Social Structure. New York: Free Press.

Blossfeld, Peter, and Götz Rohwer. 1995. Techniques of Event History Modeling: New Approaches to Causal Analysis. Mahwah, N.J.: Erlbaum.

$\rightarrow$ Brewster, Karin L. 1994. "Race Differences in Sexual Activity among Adolescent Women: The Role of Neighborhood Characteristics." American Sociological Review 59:408-24.

Brooks-Gunn, Jeanne, and Roberta L. Paikoff. 1993. "Sex Is a Gamble, Kissing Is a Game': Adolescent Sexuality and Health Promotion." Pp. 180-208 in Promoting the Health of Adolescents. New Directions for the Twenty-First Century, edited by Susan G. Millstein, Anne C. Petersen, and Elena O. Nightingale. New York: Oxford University Press.

Brown, B. B., and Wendy Theobald. 1999. "Peers Matter: A Research Synthesis of Peer Influences on Adolescent Pregnancy." Washington, D.C.: National Campaign to Prevent Teen Pregnancy.

Brückner, Hannah. 1995. "People Don't Lie, Surveys Do? An Analysis of Data Quality in a Retrospective Life Course Study." Materialien aus der Bildungsforschung Nr. 50. Max Planck Institute for Human Development, Berlin.

Calhoun, Craig. 1991. "The Problem of Identity in Collective Action"Pp. 51-75 in Macro-Micro Linkages in Sociology, edited by Joan Huber. Beverly Hills, Calif.: Sage.

Dittus, Patricia J., and James Jaccard. 1998. "Adolescent Perceptions of Maternal Disapproval of Sex and the Mother-Adolescent Relationship: The Impact on Sexual Outcomes." Manuscript. University at Albany, State University of New York, Department of Psychology.

Furstenberg, Frank. 1976. Unplanned Parenthood: The Social Consequences of Teenage Childbearing. New York: Free Press.

$\rightarrow$ Furstenberg, Frank, Jeanne Brooks-Gunn, and S. P. Morgan. 1987. "Race Differences in the Timing of Sexual Intercourse." American Sociological Review 52:511-18.

$\rightarrow$ Guo, Guang. 1993. "Event-History Analysis for Left-Truncated Data." Sociological Methodology 23:217-43.

Guttentag, Marcia, and Paul Secord. 1983. Too Many Women? The Sex-Ratio Question. Newbury Park, Calif.: Sage.

$\rightarrow$ Halpern, Carolyn T., Kara Joyner, Richard J. Udry, and C. Suchindran. 2000. "Smart Teens Don't Have Sex (or Kiss Much Either).” Journal of Adolescent Health 26 (3): 213-25.

Hardin, Russell. 1995. One for All: The Logic of Group Conflict. Princeton, N.J.: Princeton University Press.

Harris, Kathleen M. 1996. "The Impact of Family Structure and Father Involvement on Risk Behavior among Adolescents." Paper presented at the NICHD (National Institute of Child Health and Human Development) Conference on Father Involvement, Bethesda, Md.: October 10-11, 1996.

Hayes, Cheryl D., ed. 1987. Risking the Future: Adolescent Sexuality, Pregnancy, and Childbearing. Washington, D.C.: National Academy Press.

Hofferth, Sandra L. 1987. "Factors Affecting Initiation of Sexual Intercourse." Pp. 7-35 in Risking the Future: Adolescent Sexuality, Pregnancy, and Childbearing, vol. 2. Edited by Sandra L. Hofferth and Cheryl D. Hayes. Washington, D.C.: National Academy Press.

$\rightarrow$ Jaccard, James, Patricia J. Dittus, and V. V. Gordon. 1996. "Maternal Correlates of 
Adolescent Sexual and Contraceptive Behavior." Family Planning Perspectives 28: $159-65$.

Joyner, Kara, and Richard J. Udry. 1998. "Adolescent Romance and Depression." Manuscript. University of North Carolina, Carolina Population Center.

Kaminer, Wendy. 1996. True Love Waits. Perseus Press.

$\rightarrow$ Kim, Hyojoung, and Peter S. Bearman. 1997. "Who Counts in Collective Action? The Structure and Dynamics of Movement Participation.” American Sociological Review. 62:70-93.

Laitin, David. 1998. Identity in Formation: The Russian- Speaking Populations in the Near Abroad.Ithaca, N.Y.: Cornell University Press.

Martin, Karin A. 1996. Puberty, Sexuality, and the Self: Boys and Girls at Adolescence. New York: Routledge.

Miller, Brent C. 1998. Families Matter: A Research Synthesis of Family Influences on Adolescent Pregnancy. Washington, D.C.: National Campaign to Prevent Teen Pregnancy.

Moore, Kristin A., Anne K. Driscoll, and Laura D. Lindberg. 1998. A Statistical Portrait of Adolescent Sex, Contraception, and Childbearing. Washington, D.C.: National Campaign to Prevent Teen Pregnancy.

Newcomer, S. F., Richard J. Udry, and F. Cameron. 1983. "Adolescent Sexual Behavior and Popularity." Adolescence 18:515-22.

Perry, Cheryl L., Steven H. Kelder, and Kelli A. Komro. 1993. "The Social World of Adolescents: Families, Peers, Schools, and the Community." Pp. 73-96 in Promoting the Health of Adolescents: New Directions for the Twenty-First Century, edited by Susan G. Millstein, Anne C. Petersen, and Elena O. Nightingale. New York: Oxford University Press.

$\rightarrow$ Resnick, Michael D., Peter S. Bearman, Robert W. Blum, Karl E. Bauman, Kathleen M. Harris, Jo Jones, Joyce Tabor, Trish Beuhring, Renee E. Sieving, Marcia Shew, Majorie Ireland, Linda H. Bearinger, and Richard J. Udry. 1997. "Protecting Adolescents from Harm: Findings from the National Longitudinal Study on Adolescent Health." Journal of the American Medical Association 278 (10): 823-32.

$\rightarrow$ Spanier, G. 1975. "Sexualization and Premarital Sexual Behavior." Family Coordinator 24:33-41.

Thompson, Sharon. 1995. Going All the Way: Teenage Girls' Tales of Sex, Romance, and Pregnancy. New York: Hill \& Wang.

$\rightarrow$ Thornton, A., and D. Camburn. 1989. "Religious Participation and Adolescent Sexual Behavior and Attitudes." Journal of Marriage and the Family Journal of Marriage and the Family 51:641-53.

$\rightarrow$ Tubman, Jonathan G., Michael Windle, and Rebecca C. Windle. 1996a. "Cumulative Sexual Intercourse Patterns among Middle Adolescents: Problem Behavior Precursors and Concurrent Health Risk Behaviors." Journal of Adolescent Health 18:182-91.

$\rightarrow \quad$. 1996b. "The Onset and Cross-Temporal Patterning of Sexual Intercourse in Middle Adolescence: Prospective Relations With Behavioral and Emotional Problems." Child Development 67:327-43.

$\rightarrow$ Turner, C. F., L. Ku, M. Rogers, L. D. Lindberg, J. H. Pleck, and F. L. Sonenstein. 1998. "Adolescent Sexual Behavior, Drug Use, and Violence: Increased Reporting With Computer Survey Technology." Science 280 (May): 867-68.

$\rightarrow$ Udry, Richard J. 1988. "Biological Predispositions and Social Control in Adolescent Sexual Behavior." American Sociological Review 53:709-22.

Udry, Richard J., and Peter S. Bearman. 1998. "New Methods for New Research on Adolescent Sexual Behavior." New Perspectives on Adolescent Risk Behavior, edited by Richard Jessor. Cambridge: Cambridge University Press.

$\rightarrow$ Udry, Richard J., and John O. G. Billy. 1987. "Initiation of Coitus in Early Adolescence." American Sociological Review 52 (6): 841-55. 
American Journal of Sociology

$\rightarrow$ Upchurch, Dawn M., Lene Levy-Storms, Clea A. Sucoff, and Carol S. Aneshensel. 1998. "Gender and Ethnic Differences in the Timing of First Sexual Intercourse." Family Planning Perspectives 30 (3): 121-27.

Whitehead, Barbara D., and Theodora Ooms. 1999. Goodbye to Girlhood: What's Troubling Girls and What We Can Do About It. Washington, D.C.: National Campaign to Prevent Teen Pregnancy. 